\title{
Stem Cell-Mediated Transfer of a Human Artificial Chromosome Ameliorates Muscular Dystrophy
}

Francesco Saverio Tedesco et al.

Sci Transl Med 3, 96ra78 (2011);

DOI: 10.1126/scitranslmed.3002342

Editor's Summary

\section{Stem Cells Muscle in on the Action}

The progressive muscle loss that is the hallmark of Duchenne muscular dystrophy (DMD) has proved very difficult to halt or reverse. Although the causative mutations of DMD were identified in the X-linked gene encoding dystrophin (a structural muscle protein) several decades ago, translating this genetic discovery into new treatments has been challenging. Most therapeutic strategies aim to use gene therapy to deliver the normal dystrophin gene to the dystrophic muscles of DMD patients. However, the dystrophin gene is too large to be carried by the viral vectors usually used in gene therapy and all muscles in the body would have to be injected with the vector and replacement gene. Now, Tedesco and colleagues combine stem cell therapy with a human artificial chromosome vector to overcome these two challenges in the mdx mouse model of DMD.

This team had previously identified a blood vessel stem cell called "mesoangioblast" that has the dual talents of being able to cross blood vessel walls and to differentiate into a variety of mesodermal cell types including muscle cells. Would these stem cells be able to deliver a replacement dystrophin gene to dystrophic muscles in the mdx mouse? Predicting that they would, Tedesco and colleagues used a human artificial chromosome vector engineered to carry the entire normal human dystrophin gene including the regulatory regions. They transferred the vector and its large cargo into mesoangioblasts isolated from mdx mice; then they injected the corrected mesoangioblasts directly into the dystrophic skeletal muscles of recipient immune-deficient mdx mice (to prevent reaction against the human protein). The authors showed that the transplanted mesoangioblasts were able to engraft in dystrophic muscles, express normal dystrophin, and produce functional muscle fibers with amelioration of dystrophic pathology. They also found that the transplanted mesoangioblasts contributed to the muscle satellite cell pool, which produces new muscle cells under normal conditions. Next, the authors showed that if they injected the corrected mesoangioblasts into the arterial circulation of mdx mice, the cells were able to cross blood vessel walls, home to dystrophic muscles and graft contribute to the formation of new dystrophin-expressing myofibers. The authors then showed that mice receiving the mesoangioblast transplants showed reduced fiber fragility, increased force, and greater motor capacity on treadmill and freewheel tests. Although there are still technical and regulatory hurdles to be overcome before this strategy can be used in DMD patients, stem cell -mediated transfer of the normal dystrophin gene using a human artificial chromosome shows promise as a treatment for this tragic and ultimately fatal disease.

A complete electronic version of this article and other services, including high-resolution figures, can be found at: http://stm.sciencemag.org/content/3/96/96ra78.full.html

Supplementary Material can be found in the online version of this article at: http://stm.sciencemag.org/content/suppl/2011/08/15/3.96.96ra78.DC1.html

Information about obtaining reprints of this article or about obtaining permission to reproduce this article in whole or in part can be found at:

http://www.sciencemag.org/about/permissions.dtl 


\title{
Stem Cell-Mediated Transfer of a Human Artificial Chromosome Ameliorates Muscular Dystrophy
}

\author{
Francesco Saverio Tedesco, ${ }^{1,2}$ Hidetoshi Hoshiya, ${ }^{1}$ Giuseppe D'Antona, ${ }^{3}$ \\ Mattia F. M. Gerli, ${ }^{1}$ Graziella Messina, ${ }^{1,4}$ Stefania Antonini, ${ }^{1}$ Rossana Tonlorenzi, ${ }^{1}$ \\ Sara Benedetti, ${ }^{1,5}$ Libera Berghella, ${ }^{6}$ Yvan Torrente, $^{7}$ Yasuhiro Kazuki, ${ }^{8}$ \\ Roberto Bottinelli, ${ }^{3,9}$ Mitsuo Oshimura, ${ }^{8}$ Giulio Cossu ${ }^{1,4 *}$
}

In contrast to conventional gene therapy vectors, human artificial chromosomes (HACs) are episomal vectors that can carry large regions of the genome containing regulatory elements. So far, HACs have not been used as vectors in gene therapy for treating genetic disorders. Here, we report the amelioration of the dystrophic phenotype in the $\mathrm{mdx}$ mouse model of Duchenne muscular dystrophy (DMD) using a combination of HAC-mediated gene replacement and transplantation with blood vessel-associated stem cells (mesoangioblasts). We first genetically corrected mesoangioblasts from dystrophic $\mathrm{mdx}$ mice with a HAC vector containing the entire (2.4 Mb) human dystrophin genetic locus. Genetically corrected mesoangioblasts engrafted robustly and gave rise to many dystrophin-positive muscle fibers and muscle satellite cells in dystrophic mice, leading to morphological and functional amelioration of the phenotype that lasted for up to 8 months after transplantation. Thus, HAC-mediated gene transfer shows efficacy in a preclinical model of DMD and offers potential for future clinical translation.

\section{INTRODUCTION}

Duchenne muscular dystrophy (DMD) is caused by mutations in the gene encoding the protein dystrophin $(1,2)$. DMD primarily affects skeletal muscles and results in progressive paralysis and premature death $(3,4)$. There is no successful treatment, but new gene therapy and stem cell transplantation strategies are under investigation $(5,6)$. However, the large size of the dystrophin gene (7) and complementary DNA (cDNA) (14 kb) (2) prevents their accommodation inside viral vectors for efficient gene delivery to muscle. Recently, we have isolated and characterized a population of blood vessel-associated stem cells, called mesoangioblasts (8), that can differentiate into multiple mesoderm cell types, including skeletal muscle. When delivered in the arterial circulation, mesoangioblasts crossed the blood vessel wall and participated in skeletal muscle regeneration, ameliorating signs of muscular dystrophy in two animal models: the $\alpha$-sarcoglycan-null (Sgca-null) mouse $(9,10)$ and the golden retriever muscular dystrophy (GRMD) dog (11). The ability of mesoangioblasts to cross blood vessel walls is a distinct advantage over canonical muscle progenitor cells such as satellite cells $(5,12)$. Cells similar to mouse mesoangioblasts have been isolated from human adult skeletal muscle and have been shown to correspond to a subset of pericytes (13). Furthermore, donor human leukocyte antigen (HLA)-matched mesoangioblasts have been expanded under clinical-grade conditions and are currently being transplanted into DMD patients in a phase I/II clinical trial at our

\footnotetext{
'Division of Regenerative Medicine, Stem Cells and Gene Therapy, San Raffaele Scientific Institute, 20132 Milan, Italy. ${ }^{2}$ Vita-Salute San Raffaele University, 20132 Milan, Italy. ${ }^{3}$ Department of Physiology and Interuniversity Institute of Myology, University of Pavia, 27100 Pavia, Italy. "Department of Biology, University of Milan, 20133 Milan, Italy. "Department of Histology and Medical Embryology, "Sapienza" University of Rome, 00161 Rome, Italy. ${ }^{6}$ Casa di Cura San Raffaele, 67039 Sulmona, L'Aquila, Italy. ${ }^{7}$ Department of Neurological Science, University of Milan, Fondazione Istituto di Ricovero e Cura a Carattere Scientifico (IRCCS) Policlinico Mangiagalli-Regina Elena, 20122 Milan, Italy. ${ }^{8}$ Department of Biomedical Science, Institute of Regenerative Medicine and Biofunction, Tottori University, Yonago 683-8503, Japan. ${ }^{9}$ Fondazione Salvatore Maugeri (IRCCS), Scientific Institute of Pavia, 27100 Pavia, Italy.

*To whom correspondence should be addressed. E-mail: cossu.giulio@hsr.it
}

institution (EudraCT no. 2011-000176-33). Autologous transfer of genetically corrected muscle progenitor cells is desirable because immune suppression would not be required. Because of the large size of the dystrophin gene and transcript, alternative strategies are being tested for their correction or replacement (14). Strategies include using a minior microdystrophin gene $(15,16)$, compensatory up-regulation of the related utrophin gene $(6,17)$, and exon $(18-21)$ or stop codon skipping (PTC124-mediated readthrough of nonsense mutations) (22). The clinical efficacy of gene therapy using a shorter dystrophin gene is only now being tested (23). On the other hand, although exon-skipping techniques show promise, they cannot be used for large deletions or to repair mutations either in regulatory regions (promoters/enhancers) or in sequences encoding the $\mathrm{N}$ - or C-terminal domains of dystrophin (19).

Human artificial chromosomes (HACs) can carry large genomic segments containing a whole genetic locus including the regulatory regions and microRNAs. HACs can be engineered to express additional beneficial functions and have the advantage of avoiding insertional mutagenesis, because they do not become integrated into the host cell DNA and remain episomal (24). The presence of internal promoters, splicing sites, and polyadenylate $[\operatorname{poly}(\mathrm{A})]$ sites allows tissue-specific expression of the therapeutic gene, making HACs suitable for gene delivery to different target cells (25-27). Despite this potential, no evidence of therapeutic efficacy has been reported for HACs in the relatively long period since they were originally engineered (28).

We reported previously the development of a HAC vector containing the entire human dystrophin genetic locus (DYS-HAC) that is stably maintained in recipient cells (25). We then demonstrated, in a proof-ofconcept study, the genetic correction of induced pluripotent stem cells derived from DMD patients (26). However, these studies were limited to analysis of dystrophin expression from a HAC vector in chimeras and teratomas derived from induced pluripotent stem cells.

Here, we established a HAC-based genomic transfer strategy for treating the dystrophic phenotype in the mdx mouse model of DMD. We used dystrophin gene delivery with the DYS-HAC vector to correct mesoangioblasts from mdx mice; the corrected cells were then transplanted 
back into dystrophic animals (29) (Fig. 1). After transplantation, the corrected mesoangioblasts containing the DYS-HAC vector restored dystrophin expression and led to morphological and functional amelioration of the dystrophic phenotype in immune-deficient $\mathrm{mdx}$ mice that lasted for several months.

\section{RESULTS}

\section{Characterization of DYS-HAC-corrected mdx mesoangioblasts}

To investigate whether the DYS-HAC vector could rescue the phenotype of $\mathrm{DMD}$ in the mdx mouse model, we first isolated mesoangioblasts from mdx dystrophic mice (Figs. 1 and 2A). After expansion, cells were subjected to microcell-mediated chromosome transfer (MMCT) (24) to introduce the DYS-HAC vector. This technique allows the fusion of microcells (small particles of nuclear and plasma membrane containing one or a few chromosomes) with whole cells and the subsequent selection of hybrids. The DYS-HAC vector contains the entire human dystrophin gene locus, a gene encoding enhanced green fluorescent

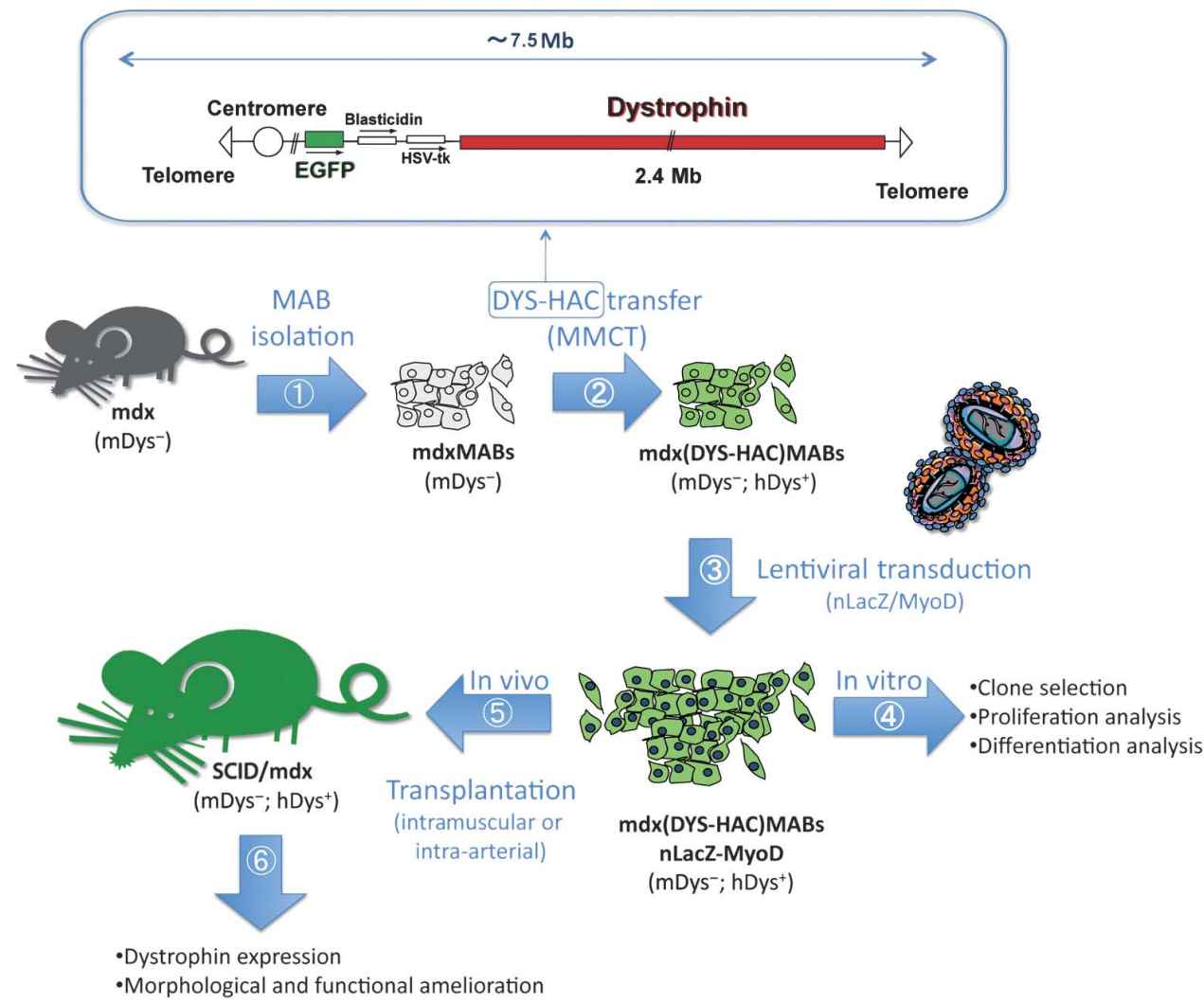

Fig. 1. Experimental strategy for mesoangioblast-mediated transfer of the DYS-HAC vector. The scheme illustrates the various steps of the process. Mesoangioblasts were first isolated from mdx dystrophic mice (1) and transduced with the DYS-HAC vector (shown in the upper part of the panel) (2); they then underwent selection. Selected clones (EGFP-positive) were then transduced with two lentiviral vectors expressing MyoD and nLacZ (3). After in vitro characterization (4), the corrected mesoangioblasts were transplanted into dystrophic SCID/mdx mice (5). The mice were then analyzed for dystrophin expression and morphological and functional recovery (6). MABs, mesoangioblasts; mdx(DYS-HAC)MABs, DYS-HAC-corrected mdx-derived mesoangioblasts; MMCT, microcell-mediated chromosome transfer; EGFP, enhanced green fluorescent protein; mDys, murine dystrophin; hDys, human dystrophin. Figures were produced using Servier Medical Art. protein (EGFP), a gene encoding the herpes simplex virus thymidine kinase (HSV-TK), and a blasticidin resistance transgene (Fig. 1).

Using MMCT, we obtained 47 drug-resistant and EGFP-positive lones; 42 of them were expanded and 24 randomly selected clones were (Table 1; efficiency of MMCT was $1.2 \times 10^{-5}$ ). Polymerase chain (PCR) analysis showed that 13 of 24 clones contained a HAC in Fig. 2B). Fluorescence in situ hybridization (FISH) (Fig. 2C) revealed that the DYS-HAC vector was present as an individual chromosome in six of eight randomly selected $\mathrm{mdx}$ mesoangioblast clones (Table 1).

These six clones (J2, J3, J13, J16, J19, and J20; Fig. 2C), which had been corrected with the DYS-HAC vector, were then characterized in vitro. The morphology and proliferative capacity of the six clones were similar to that of parental mdx mesoangioblasts (Fig. 2, C and D). Likewise, telomerase activity was maintained in all of the clones anaed (fig. S1). Although the cells were characterized by a marked pro(SCID) mice demonstrated no tumor formation even after 10 months of follow-up. Clones J2 and J3 were then selected as the best candidates for further experiments because they were similar in morphology, proliferation, and surface markers to the parental mdx mesoangioblasts (Fig. 2, C and E). Flow cytometric analysis confirmed homogeneous EGFP expression (Fig. 2E) even after 10 population doublings in culture without selection. These results demonstrate that $\mathrm{mdx}$ mesoangioblasts maintain their original properties and clonogenicity after MMCT.

Like embryonic mesoangioblasts (8), mdx mesoangioblasts do not spontaneously differentiate into skeletal myocytes in culture. To test their myogenic potential, we cocultured J2 and J3 clones transduced with a nuclear LacZ (nLacZ) lentiviral vector with the $\mathrm{C} 2 \mathrm{C} 12$ myoblast cell line. After 72 hours in differentiation medium, EGFP-positive myotubes appeared (Fig. 2F), demonstrating that DYS-HAC-corrected mdx mesoangioblasts had fused with $\mathrm{C} 2 \mathrm{C} 12$ cells. After 1 week, up to $7 \%$ of nuclei in myotubes were positive for the X-gal reaction, which reveals $\beta$-galactosidase-positive nuclei (Fig. 2F), confirming the ability of DYS-HAC-corrected mdx mesoangioblasts to fuse with differentiating myoblasts. To further test their myogenic potential, we induced differentiation of DYS-HAC-corrected mdx mesoangioblasts by transfer of the cDNA encoding MyoD (31), a master transcription factor that only cells with latent myogenic potential can respond to efficiently (32). Ninety-six hours after serum withdrawal, multinucleated myotubes that stained positive for MyoD and myosin heavy chain were observed in vitro 
Fig. 2. Characterization of DYSHAC-corrected mdx mesoangioblasts. Shown is the isolation and characterization of mesoangioblasts from $\mathrm{mdx}$ dystrophic mice corrected with a HAC vector carrying the human dystrophin gene (DYS-HAC) and the testing of their myogenic potential. (A) Representative morphology of $\mathrm{mdx}$ mesoangioblasts (scale bar, $50 \mu \mathrm{m}$ ). (B) PCR analysis showing mutant $\mathrm{mdx}$ mouse dystrophin and human dystrophin in a representative clone (details in Table 1). WT-MABs, wild-type mesoangioblasts; mdxMABs, mdx mesoangioblasts; mdx(DYS-HAC)MABs, DYS-HAC-corrected mdx mesoangioblasts. (C) Representative images of six selected clones analyzed by FISH (upper row; arrow indicates the episomal DYS-HAC vector; scale bar, $5 \mu \mathrm{m}$ ), phase contrast (lower row), and EGFP fluorescence (middle row; scale bar, $100 \mu \mathrm{m})$. (D) Growth curves of corrected mdx mesoangioblast clones compared with the parental population (experiments with each clone in duplicate). (E) Fluorescenceactivated cell sorting analysis of the $\mathrm{J} 2$ and $\mathrm{J} 3$ clones selected for further experiments. Dot plots refer to EGFP fluorescence, and histograms to different surface markers. (F) (Left) Live imaging of EGFPpositive myotubes (white arrowhead) after coculture of corrected mdx mesoangioblasts with $\mathrm{C} 2 \mathrm{C} 12$ myoblasts (EGFP-negative). (Right) Immunohistochemistry of cocultured cells showing hybrid myosin heavy chain (MyHC)-positive myotubes containing $\mathrm{X}$-gal-positive nuclei (black arrowheads) from the nLacZ-transduced mdx-corrected mesoangioblast clone J2 (scale bars, $40 \mu \mathrm{m})$. Graph shows quantification of mesoangioblast-myotube fusion $(n=4)$. (G) In vitro differentiation of corrected mdx mesoangioblasts into skeletal muscle. (Main panel) Immunofluorescence and X-gal staining of nLacZ- and MyoD-transduced corrected $\mathrm{mdx}$ mesoangioblasts cultured in differentiation medium (scale bar, $120 \mu \mathrm{m}$; the magnification displays multinucleated myotubes and myocytes). (Right) Immunofluorescence showing homogeneous (100\%) MyoD and EGFP expression from J2 cells after eight population doublings (scale bar, $70 \mu \mathrm{m}$ ). (H) Immunofluorescence (scale bar, $60 \mu \mathrm{m}$ ) and Western blot demonstrating production of myosin heavy chain and dystrophin by differentiated ( 10 days) J2 corrected mdx mesoangioblasts (transduced with the
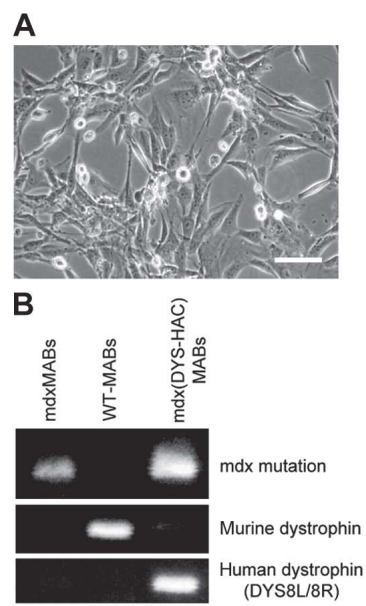

हु 250$] \rightarrow$ mdxMABs

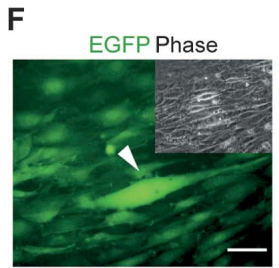

Days

$\mathrm{H}$
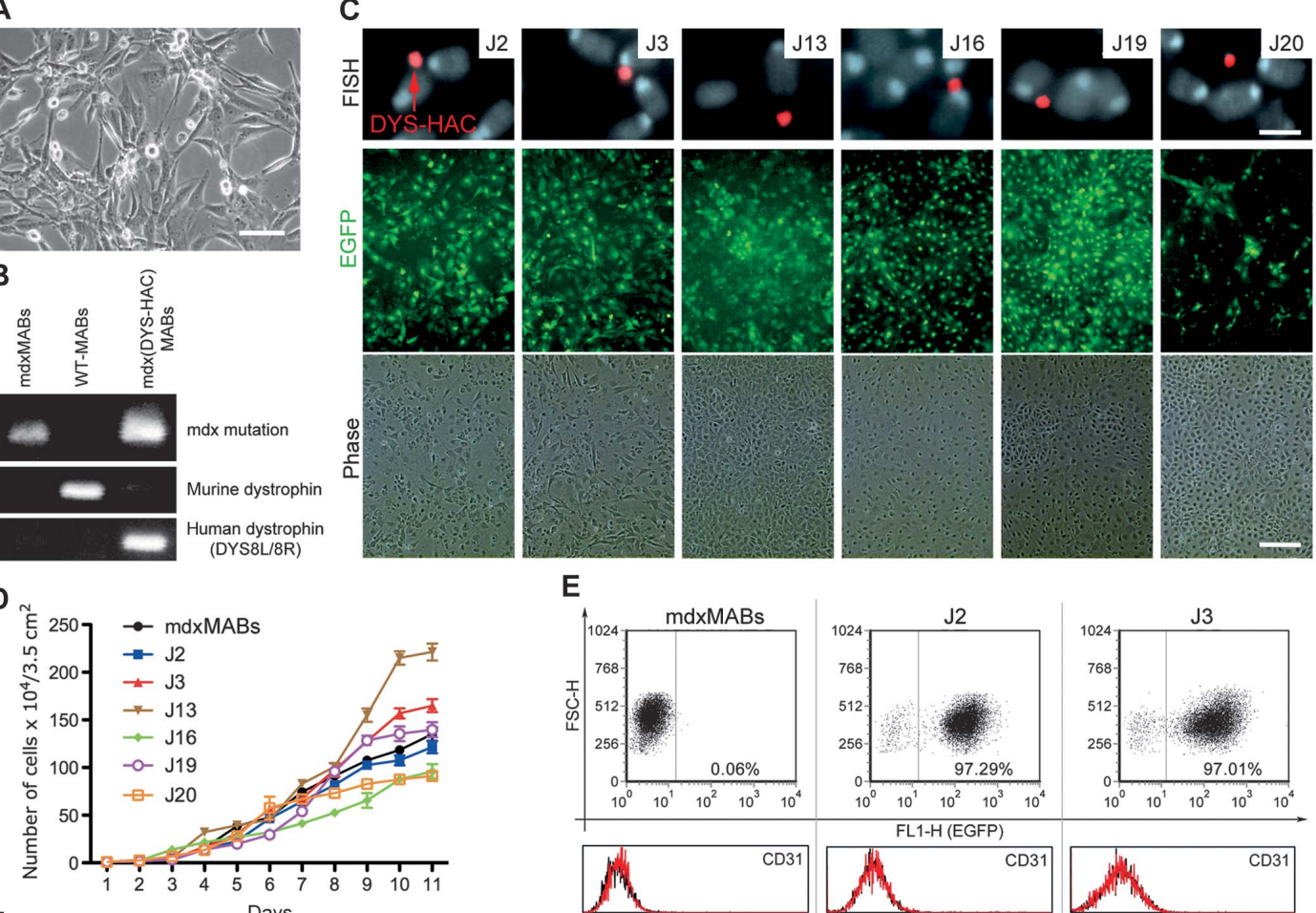

E
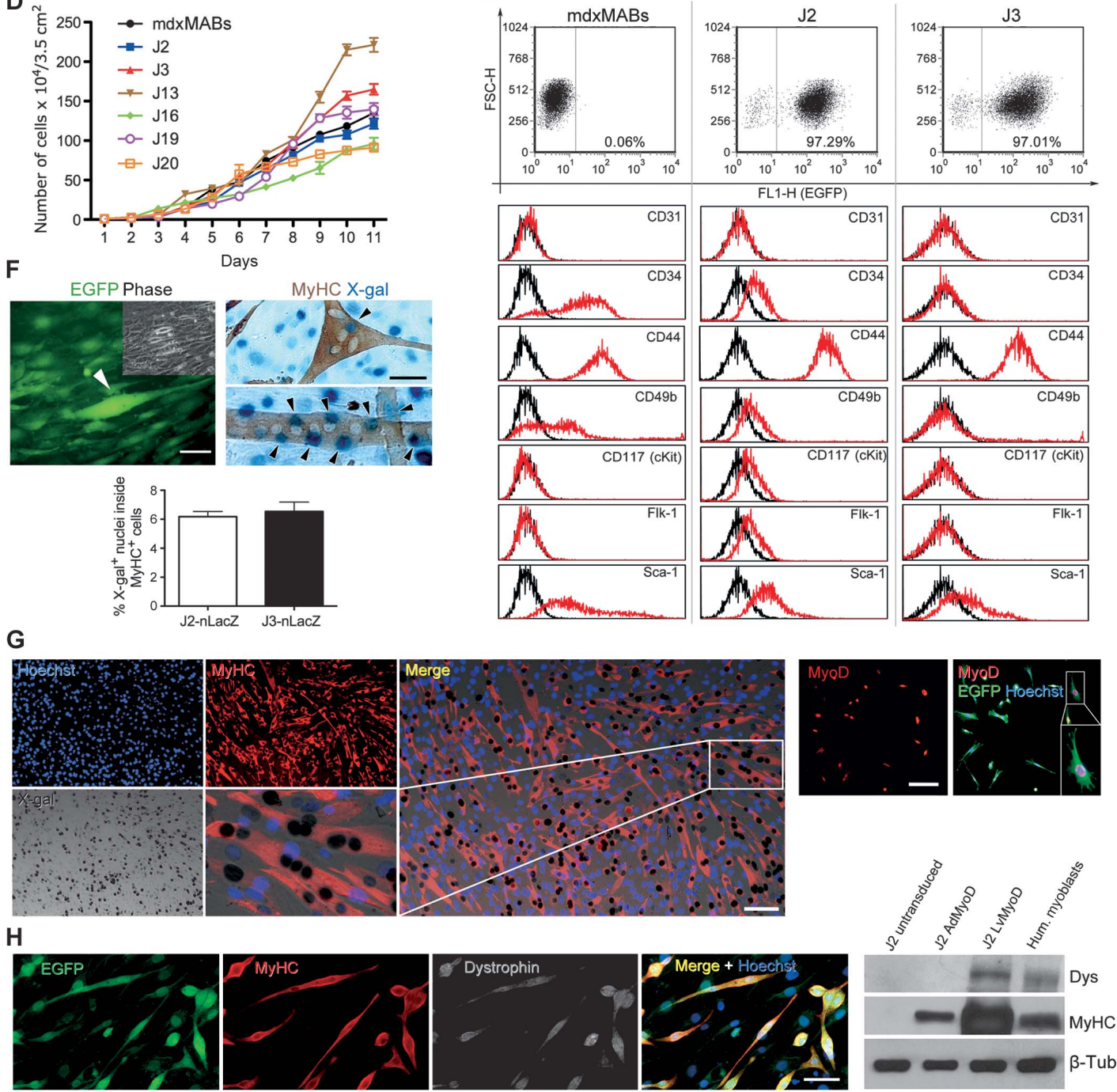

lentiviral vector carrying MyoD cDNA). The Western blot also shows J2 corrected mdx mesoangioblasts transduced with adenoviral MyoD (AdMyoD), which were used as a standard assay for myogenic conversion. (Differentiated human myoblasts were used as a positive control.) Error bars represent SEM and images are representative of a minimum of five independent experiments. $\beta$-Tub, $\beta$-tubulin. 
Table 1. Analysis by PCR and FISH of all selected EGFP-positive mdx mesoangioblast clones containing the DYS-HAC vector. Clones were analyzed by PCR for expression of different regions of the human dystrophin gene (representative panel in Fig. $4 \mathrm{~B}$ ) and different regions of the HAC vector. The PCR-positive clones were tested by FISH to see whether the DYS-HAC vector was episomal and to test its stability. A detailed list of the primers is available in the Supplementary Material. $\mathrm{CHO}$, Chinese hamster ovary cells (positive control); DYS-HAC, human artificial chromosome containing the entire human dystrophin; mdxMABs, uncorrected parental $\mathrm{mdx}$ mouse mesoangioblasts (negative control); + , positive; -, negative; NA, not applicable (impaired growth); NT, not tested; $Y$, yes; $\mathrm{N}$, no.

PCR

\begin{tabular}{|c|c|c|c|c|c|c|c|c|c|}
\hline \multirow[b]{3}{*}{ Clones } & \multirow[b]{3}{*}{$\begin{array}{l}\text { Growth } \\
\text { under } \\
\text { selection }\end{array}$} & \multicolumn{7}{|c|}{ PCR } & \multirow{3}{*}{$\begin{array}{c}\text { FISH } \\
\text { HAC } \\
\begin{array}{c}\text { episomal } \\
\text { presence }\end{array}\end{array}$} \\
\hline & & \multicolumn{5}{|c|}{$\begin{array}{c}\text { First screening } \\
\text { (primers for different human dystrophin regions) }\end{array}$} & \multicolumn{2}{|c|}{$\begin{array}{l}\text { Second screening } \\
\text { (primers for different HAC regions) }\end{array}$} & \\
\hline & & $\begin{array}{l}\text { DYS } \\
3 L / 3 R\end{array}$ & $\begin{array}{l}\text { DYS } \\
6 \mathrm{~L} / 6 \mathrm{R}\end{array}$ & $\begin{array}{l}\text { DYS } \\
\text { 7L/7R }\end{array}$ & $\begin{array}{l}\text { DYS } \\
\text { 7L/8R }\end{array}$ & $\begin{array}{l}\text { DYS } \\
\text { 8L/8R }\end{array}$ & Sk23/DYSt5R & EGFPL/\#21CenG6R & \\
\hline mdxMABs J1 & Y & + & + & + & - & + & NT & NT & NT \\
\hline $\operatorname{mdxMABs} J 2^{*}$ & Y & + & + & + & + & + & + & + & + \\
\hline mdxMABs J3* & $\mathrm{Y}$ & + & + & + & + & + & + & + & + \\
\hline mdxMABs J4 & Y & + & + & + & + & + & + & + & - \\
\hline mdxMABs J5 & Y & + & + & + & + & + & + & + & - \\
\hline mdxMABs J6 & Y & + & - & - & - & - & NT & NT & NT \\
\hline mdxMABs J7 & $\mathrm{N}$ & NA & NA & NA & NA & NA & NA & NA & NA \\
\hline mdxMABs J8 & $\mathrm{N}$ & NA & NA & NA & NA & NA & NA & NA & NA \\
\hline mdxMABs & $\mathrm{Y}$ & + & + & + & + & + & + & + & NT \\
\hline mdxMABs J10 & $\mathrm{Y}$ & + & - & - & - & - & NT & NT & NT \\
\hline mdxMABs J11 & $\mathrm{Y}$ & + & - & - & - & - & NT & NT & NT \\
\hline mdxMABs J12 & $\mathrm{N}$ & NA & NA & NA & NA & NA & NA & NA & NA \\
\hline mdxMABs $J 13^{*}$ & Y & + & + & + & + & + & + & + & + \\
\hline mdxMABs J14 & $\mathrm{Y}$ & + & - & - & - & - & NT & NT & NT \\
\hline mdxMABs J15 & Y & + & + & + & - & + & NT & NT & NT \\
\hline mdxMABs J16* & $\mathrm{Y}$ & + & + & + & + & + & + & + & + \\
\hline mdxMABs J17 & $\mathrm{N}$ & NA & NA & NA & NA & NA & NA & NA & NA \\
\hline mdxMABs J18 & $\mathrm{N}$ & NA & NA & NA & NA & NA & NA & NA & NA \\
\hline mdxMABs J19* & $Y$ & + & + & + & + & + & + & + & + \\
\hline mdxMABs J20* & $\mathrm{Y}$ & + & + & + & + & + & + & + & + \\
\hline mdxMABs $J 21$ & $Y$ & + & - & - & - & - & NT & NT & NT \\
\hline mdxMABs J22 & $\mathrm{Y}$ & - & - & - & - & - & NT & NT & NT \\
\hline mdxMABs $J 23$ & $\mathrm{Y}$ & + & + & + & + & + & + & + & NT \\
\hline mdxMABs J24 & $\mathrm{Y}$ & - & + & + & + & + & NT & NT & NT \\
\hline mdxMABs $J 25$ & $\mathrm{Y}$ & - & + & + & + & + & NT & NT & NT \\
\hline$m d x M A B s J 26$ & Y & + & + & + & + & + & + & + & NT \\
\hline mdxMABs $J 27$ & $\mathrm{Y}$ & + & + & + & + & + & + & + & NT \\
\hline mdxMABs J28 & Y & - & + & + & + & + & NT & NT & NT \\
\hline mdxMABs J29 & $\mathrm{Y}$ & + & + & + & + & + & + & + & NT \\
\hline $\begin{array}{l}\text { mdxMABs } \\
\quad \text { (parental) }\end{array}$ & $\mathrm{N}$ & - & - & - & - & - & - & - & - \\
\hline CHO DYS-HAC & $\mathrm{Y}$ & + & + & + & + & + & + & + & + \\
\hline $\begin{array}{l}\text { Positive/analyzed } \\
\text { clones }\end{array}$ & $24 / 29$ & & & $13 / 24$ & & & & $13 / 13$ & $6 / 8$ \\
\hline
\end{tabular}

*Clones selected for in vitro characterization. 
(Fig. 2G). DYS-HAC-corrected mdx mesoangioblasts transduced with the lentiviral vector carrying the MyoD gene were maintained stably in culture without loss of their myogenic potential (see also the Supplementary Material). Also, these cells underwent terminal skeletal muscle differentiation as demonstrated by expression of mouse myosin heavy chain and human dystrophin (Fig. 2G). Together, these results show that DYS-HAC-corrected mesoangioblasts have a myogenic potential that is activated upon fusion with myoblasts or after exposure to MyoD.

Amelioration of the dystrophic phenotype in SCID/mdx mice To avoid any possible immune rejection due to expression of human dystrophin and other transgenes by DYS-HAC-corrected mdx mesoangioblasts, we used SCID/mdx mice for the transplantation studies because these mice do not reject cells expressing human genes (33). We injected $10^{6}$ DYS-HAC-corrected mdx mesoangioblasts previously transduced with nLacZ (to improve their detection) and MyoD (to improve their differentiation into skeletal muscle) into 4-month-old SCID/mdx mice. Three intramuscular injections into the tibialis anterior, gastrocnemius, and quadriceps muscles were administered bilaterally every 3 weeks and after exercise, which exacerbates dystrophic pathology (34) and enhances the recruitment of donor cells (33). Muscles receiving injections of DYS-HAC-corrected mdx mesoangioblasts showed extensive engraftment as visualized by EGFP fluorescence (Fig. 3, A and B; average EGFP-positive fibers \pm SEM: $361 \pm 87$ for tibialis anterior; $310 \pm 42$ for gastrocnemius; $270 \pm 35$ for quadriceps) and large areas of X-galpositive nuclei and dystrophin-positive fibers (Fig. 3, B and C, and fig. S2; X-gal-positive nuclei \pm SEM/tibialis anterior: $786 \pm 194$; dystrophinpositive fibers \pm SEM/tibialis anterior: $285 \pm 36$ ). In addition, reverse transcription-PCR (RT-PCR) analysis of treated mice demonstrated expression of muscle-specific human dystrophin (7) (Dp427m isoform; Fig. 3D). Immunohistochemical and Western blot analyses of the transplanted muscle revealed reconstitution of the dystrophin protein complex as shown by $\alpha$-sarcoglycan expression and its correct membrane localization (Fig. 3, B and E). Histological and biochemical analysis of muscles receiving mesoangioblast injections demonstrated amelioration of the morphological signs of the dystrophic phenotype, with reduced infiltration of muscle by mononuclear cells and reduced expression of inflammatory factors (Fig. 3, C to E, and table S2) $(35,36)$. In particular, Western blot analysis showed that the transplanted muscles of dystrophic mice produced $25 \%$ of the amount of dystrophin produced by muscles of healthy control mice (Fig. 3E; $24 \pm 7 \%$ SEM; see the Supplementary Material for details). Morphometric analyses revealed a marked reduction in the fibrotic and cellular infiltrates of treated dystrophic muscles (by about one-third; Fig. 3F and fig. S2) together with a reduction in necrotic and centrally nucleated muscle fibers, indicating that treated muscle underwent fewer degeneration-regeneration cycles. Moreover, measuring the cross-sectional area of skeletal muscles (10) in treated versus untreated SCID/mdx mice and SCID control mice revealed a partial normalization in treated SCID/mdx mice (Fig. 3F). This was shown by a reduced variability range (indicated by the size of the box in a boxand-whisker plot) and by a reduction in extreme values (indicated by the error bars) of the cross-sectional area of muscle fibers [Fig. 3F; ${ }^{\star} P<0.05$; ${ }^{* * *} P<0.0005$, one-way analysis of variance (ANOVA)].

\section{Long-term effects and contribution to the muscle satellite cell pool}

We then tested DYS-HAC-corrected mdx mesoangioblasts for longterm stability of the DYS-HAC vector and fidelity of dystrophin gene expression in vitro and in vivo (Fig. 4). FISH and PCR analyses demonstrated that the HAC vector was not integrated into the host genome (Fig. 4A) and that it contained the correct series of human dystrophin gene regions after more than 30 population doublings in vitro and after 8 months in vivo (Fig. 4B). RT-PCR confirmed correct tissue-specific expression of the human dystrophin gene (Fig. 4C). Notably, areas containing donor-derived X-gal-positive nuclei $(132 \pm 28$ $\mathrm{SEM} /$ tibialis anterior section) associated with muscle fibers positive for EGFP $(220 \pm 19$ SEM $)$ and dystrophin $(186 \pm 32$ SEM $)$ were detected for up to 8 months after transplantation of corrected mdx mesoangioblasts (Fig. 4, D to F); this observation was confirmed by Western blot analysis (Fig. 4G). This was likely due to a cumulative positive effect of the mechanical stability conferred by full-length dystrophin (which reduces degeneration-regeneration cycles) together with the contribution of transplanted DYS-HAC-corrected mdx mesoangioblasts to the pool of muscle progenitor cells. Indeed, we found that $4.53 \pm 0.53 \%$ (mean \pm SEM, $n=5$ muscles; 3 tibialis anterior and 2 gastrocnemius; $\geq 50$ sections per muscle analyzed) of Pax7-positive cells in long-term transplanted and serially exercised muscles were $\beta$-galactosidase ( $\beta$-gal)positive satellite cells derived from mesoangioblasts ( $\mathrm{Pax} 7$ is a satellite cell marker) (Fig. 4H).

Donor mesoangioblasts also allowed transplanted dystrophic muscles to sustain an additional cycle of regeneration after acute injury. This was shown by the de novo appearance of EGFP-positive donorderived muscle fibers after injection of cardiotoxin, which induces necrosis and loss of the original engrafted fibers in the same tibialis anterior muscle (Fig. 4I). Furthermore, purification of muscle satellite cells by flow cytometry from cardiotoxin-injured regenerated muscles demonstrated that most EGFP-positive mononuclear cells (>90\%) were satellite cells and that $7 \%$ of the Pax7-positive satellite cell pool was derived from donor mesoangioblasts that stably maintained the DYS-HAC vector as a single separate chromosome (Fig. 4J). Thus, donor DYS-HAC-corrected mdx mesoangioblasts are able to stably engraft, self-renew, and replenish the satellite cell pool in the treated skeletal muscles of SCID/mdx mice.

\section{Intra-arterial delivery of corrected mesoangioblasts to SCID/mdx mice}

Mesoangioblasts have the ability to cross blood vessel walls after intraarterial delivery (10). To test this property in DYS-HAC-corrected mdx mesoangioblasts, we transplanted $10^{6}$ of these cells expressing MyoD and $\mathrm{nLaCZ}$ by injection into the femoral artery of SCID/mdx mice that had been on an exercise regimen (see above). At 12 hours after injection, we detected X-gal-positive cells associated with CD31-positive skeletal muscle blood vessels (Fig. 5, A to C); a minority of them were already detectable inside myofibers (Fig. 5B). This contribution was even more evident at 36 hours (Fig. 5, D and E), with most of the cells uniformly dispersed in the downstream muscles (Fig. 5F and fig. S3). Three weeks later, clusters of EGFP-, X-gal-, and dystrophin-positive fibers were evident (Fig. 5, G to J, fig. S3, and table S1) and were clearly identifiable up to 10 weeks after transplantation (Fig. 5M). These results were also validated biochemically: Skeletal muscle-specific dystrophin transcripts (Fig. 5K) and protein (Fig. 5L) were detected at about $13 \pm 5 \%$ (mean \pm SEM) of those in the positive control. Morphometric analysis of muscle for fibrotic/adipose infiltrates and cross-sectional area in the three populations of mice revealed amelioration of histological changes in the skeletal muscle in treated mice (Fig. $5 \mathrm{~N}$ ). These results demonstrate the ability of corrected mdx mesoangioblasts to 
Fig. 3. Intramuscular transplantation of corrected mdx mesoangioblasts in SCID/mdx mice. Engraftment and differentiation, and morphological amelioration of the dystrophic phenotype in $\mathrm{SCID} / \mathrm{mdx}$ mice intramuscularly transplanted with mdx mesoangioblasts corrected by transfer of a DYS-HAC vector carrying the normal human dystrophin gene. (A) Representative images showing the tibialis anterior, gastrocnemius, and quadriceps muscles that received three intramuscular injections of $10^{6}$ corrected mdx mesoangioblasts. Images show engraftment of donor cells demonstrated by EGFP fluorescence (green) 3 weeks after the last injection (scale bar, $2 \mathrm{~mm}$ ). (B) Immunohistochemical staining showing a cluster of about 150 dystrophin-positive fibers, some of which contain X-galpositive donor nuclei (tibialis anterior muscle). (Upper inset) EGFP fluorescence on the same section before staining for dystrophin. (Lower inset) Sgca-positive myofibers in a serial section of the area delimited by dashed lines (scale bar, $100 \mu \mathrm{m}$ ). (C) Staining of muscle with $\mathrm{H} \& \mathrm{E}+\mathrm{X}$-gal (top row), Masson trichrome (middle row), and staining for dystrophin + H\&E (bottom row). Rows show transplanted (left column) versus untransplanted (central column) tibialis anterior (TA) muscles in SCID/mdx mice and SCID mice (right column) 3 weeks after the last transplantation and after nine treadmill running tests (scale bar, $200 \mu \mathrm{m}$ ). Insets depict the same field in serial sections, with the bottomleft inset depicting a larger area to show the different pattern of dystrophin-positive fibers (48 dystrophin-positive fibers of 89 fibers; scale bar, $100 \mu \mathrm{m}$ ). Central column inset shows two revertant fibers (enlarged twofold). The graph quantifies donor myofibers in transplanted tibialis anterior muscles $(n=4)$. (D) RT-PCR showing expression of musclespecific (Dp427m) and brain-specific (Dp140) human dystrophin isoforms together with inflammation-related growth factors (Hgf and Vegf-b). Lane 1, differentiated corrected mdx mesoangioblasts; lane 2, untreated SCID/mdx tibialis anterior muscle; lane 3, treated SCID/mdx tibialis anterior muscle; lane 4, untreated SCID tibialis anterior muscle; lane 5, human brain; lane 6, human skeletal muscle. (E) Western blot showing dystrophin (Dys; 427 kD), Sgca (50 kD), and CD11b (170 kD) proteins in transplanted and control tibialis anterior muscles. Different gels (separated by the black line) are in the panel. The top gel has half the amount of protein loaded for the untreated SCID mouse muscle-positive control to avoid titrating of the antibody. (F) Morphometric analysis of transplanted muscles. (Top graph) Quantification of fibrosis in treated versus untreated mice showing a reduction in the fibrosis index in treated mice $\left(n=3 ;{ }^{*} P<0.05 ;{ }^{* *} P<0.0005\right.$, one-way ANOVA). (Center graph) Distribution of cross-sectional area (CSA) values for myofibers (a minimum of 1000 myofibers per mouse and three mice per group) in H\&E-stained cryosections of tibialis anterior muscles from treated and untreated SCID/mdx mice together with untreated SCID mice. (Bottom graph) The CSA data are represented in a box-and-whisker plot, which shows the median CSA or 50th percentile (indicated by the line in the middle of the box), the 75th percentile (the top of the box), the range of CSAs (the width of the box), and the smallest and largest CSAs (the top and bottom of the "whiskers"). Significance between the groups was assessed using one-way ANOVA followed by Bonferroni post test: ${ }^{*}<<$ $0.05 ;{ }^{* * *} P<0.0005$. Images are representative of data from a minimum of nine independent experiments. Error bars represent SEM. Additional data in fig. S2 and table S2.
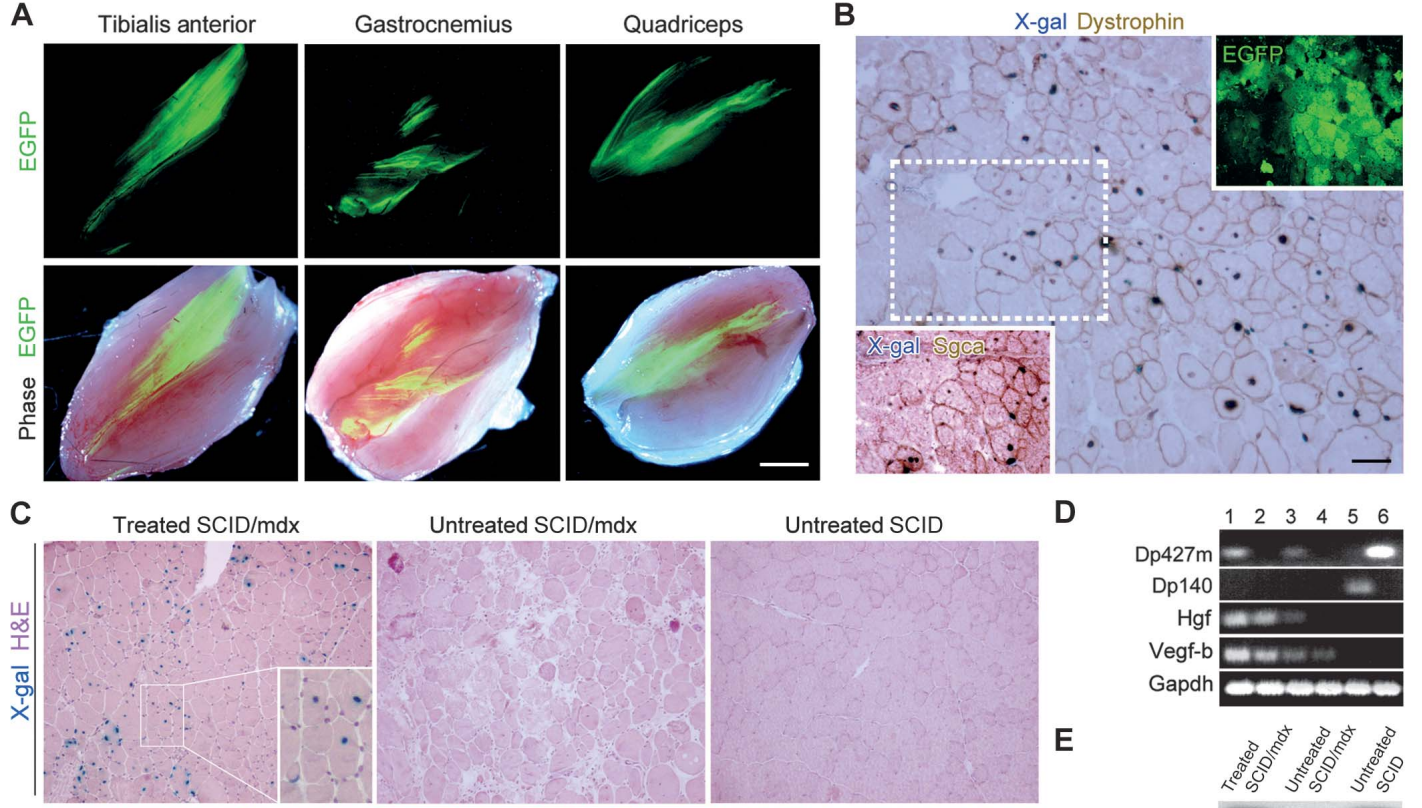

E
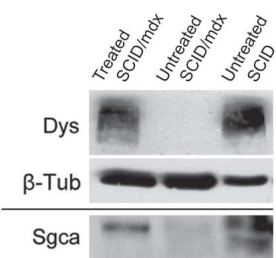
CD11b

Gapdh
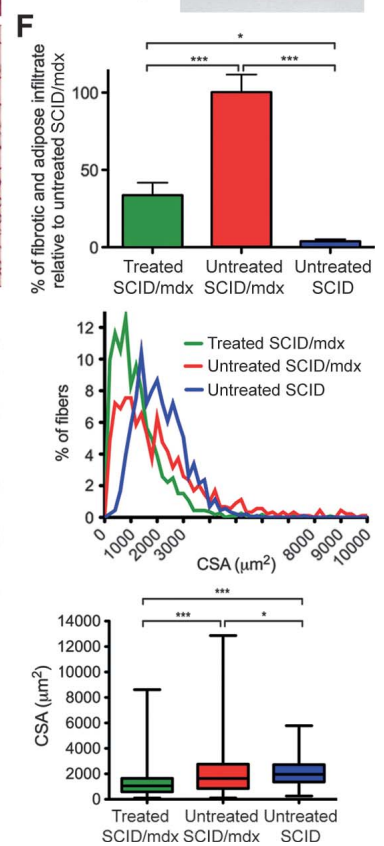

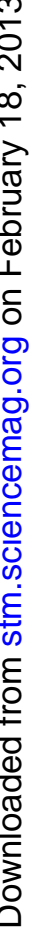


Fig. 4. Long-term stability of DYS-HAC and contribution of corrected cells to the satellite cell pool. (A) FISH images of corrected $\mathrm{mdx}$ mesoangioblasts of the $\mathrm{J} 2$ clone after long-term culture ( $>30$ population doublings). Left image shows a single DYS-HAC chromosome in an interphase nucleus (scale bar, $5 \mu \mathrm{m}$ ). Right image shows a nonintegrated DYS-HAC vector together with some host chromosomes (scale bar, $1 \mu \mathrm{m})$. (B) The PCR panel on the left shows serial human dystrophin gene regions (as shown in Table 1) maintaining the correct sequence after long-term culture of corrected $\mathrm{mdx}$ mesoangioblasts from the J2 clone (lane 2) and J3 clone (lane 3). Lane 1, donor (DYS-HAC) CHO cells (positive control); lane 4, mdx mesoangioblasts without HAC (negative control); lane 5 , human mesoangioblasts (positive control); lane 6, $\mathrm{H}_{2} \mathrm{O}$ control. The PCR panel on the right shows maintenance of the correct sequences of the human dystrophin gene in vivo 8 months after transplantation; the analysis was done with CDNA retrotranscribed from RNA to enhance detection. Lane 7, tibialis anterior muscle injected intramuscularly with DYS-HACcorrected mdx mesoangioblasts; lane 8 , untransplanted $\mathrm{SCID} / \mathrm{mdx}$ tibialis anterior muscle (negative control); lane 9, human muscle (positive control); lane 10, $\mathrm{H}_{2} \mathrm{O}$ control. (C) RT-PCR analysis of skeletal muscle-specific human dystrophin (Dp427m) expression in two different tibialis anterior muscles (lanes 2 and 3) 8 months after transplantation; Dp140, brain-specific isoform of human dystrophin. Lane 1, J2 corrected mdx mesoangioblasts; lane 4, human skeletal muscle (positive control); lane 5, human brain CDNA (negative control); lane $6, \mathrm{H}_{2} \mathrm{O}$ control. (D) Representative images with large areas of EGFP-positive myofibers (green) (inset depicts striations, enlarged 2.5 -fold) containing donor nuclei (blue) (scale bar, $2 \mathrm{~mm} ; n=24$ muscles analyzed) explanted 8 months after the last injection and stained with X-gal. (E) Immunohistochemical staining for X-gal and dystrophin of a tibialis anterior muscle section 8 months after intramuscular transplantation (scale bar, $100 \mu \mathrm{m})$. (Insets) Different images of tibialis anterior muscles that have been used for the analysis of force determination in Fig. 6E. (F) Donor cell engraftment, dystrophin production, and amelioration of morphological defects in tibialis anterior muscle from a treated SCID/mdx mouse compared with an untreated SCID/mdx mouse. Insets show Masson trichrome staining. ${ }^{*}, \S,^{\circ}$, and \# indicate strong, intermediate, weak, and no dystrophin positivity, respectively (scale bar, $100 \mu \mathrm{m}$ ). (G) Western blot demonstrating dystrophin and Sgca proteins in a tibialis anterior muscle 8 months after transplantation (lane 1); lane 2, negative control; lane 3, positive control (half protein amount loaded). (H) Immunofluorescence staining of a tibialis anterior muscle section (8 months after cell transplantation) for the satellite cell marker Pax7, $\beta$-gal (donor cells), laminin (basal lamina), and Hoechst (nuclei). The images in the upper row depict two $\beta$-gal-positive nuclei, one of which is centrally located (arrow) with the other one staining positive for Pax7 localized underneath the basal lamina (arrowhead) of the same myofiber. Lower row images display a field of the same section with a Pax7-positive/ $\beta$-gal-negative host satellite cell and a Pax7-negative/ $\beta$-gal-positive donorderived myonucleus (scale bar, $100 \mu \mathrm{m}$ ). (I) The central panel contains stereoscopic images of EGFP expression in tibialis anterior muscles that did or did not receive cellular transplants [intramuscular (IM)] and that were or were not subjected to cardiotoxin (CTX) injury (details in the Supple-
B
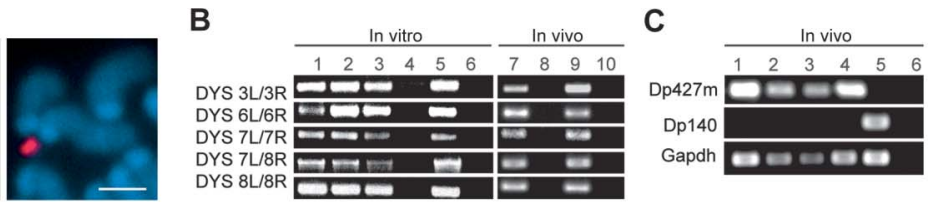

E
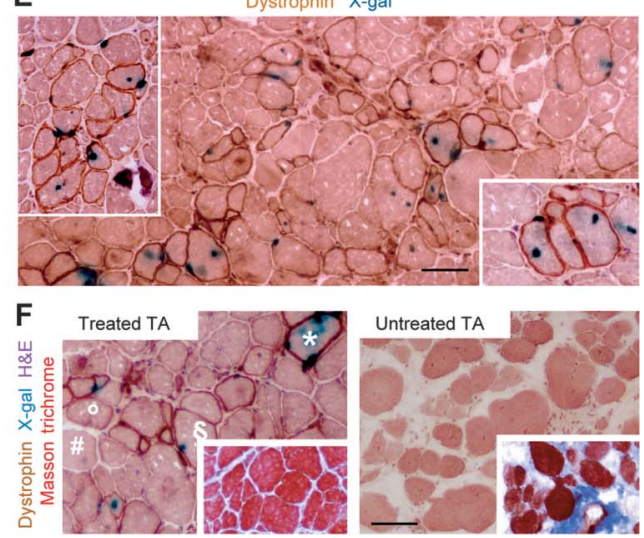

1: Treated SCID/mdx 3: Untreated SCID
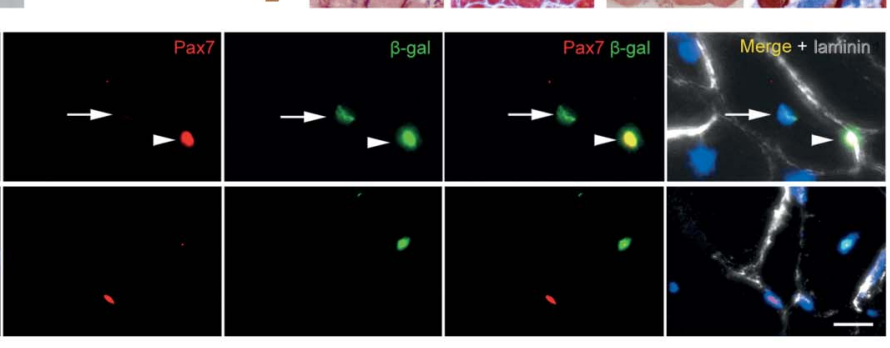

21 days post-IM; 24 days post-IM:
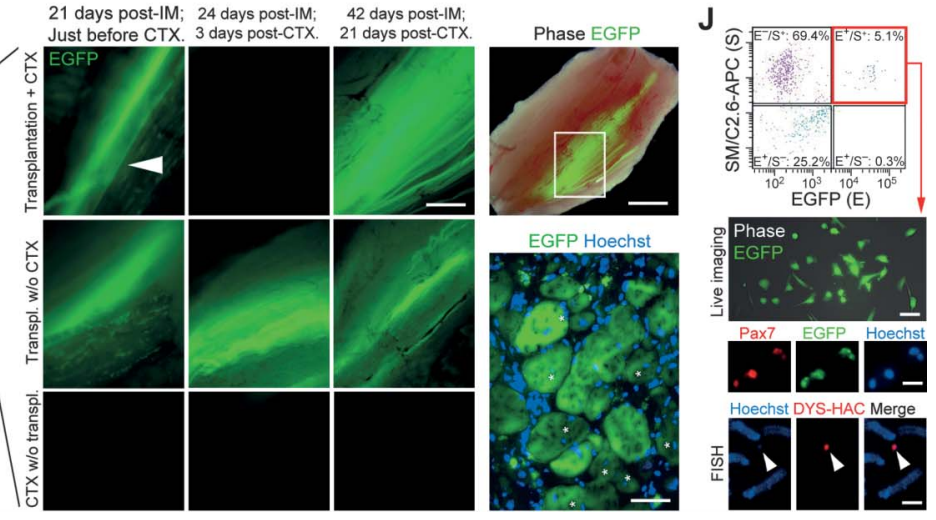

mentary Material). (Bottom left) Quantification of fluorescence (mean gray value; $n=10$ muscles; ${ }^{* *} P<0.005$, one-way ANOVA; n.s., not significant; scale bar, $0.5 \mathrm{~mm}$ ). Top far-right image is a low-magnification view of the top right picture of the central panel merged with phase contrast (area in the white square; scale bar, $2 \mathrm{~mm}$ ). Bottom far right picture is a representative high-magnification image of a transverse section of the same muscle showing EGFP-positive regenerating centrally nucleated myofibers (asterisks; scale bar, $60 \mu \mathrm{m}$ ). (J) The dot plot shows different cell populations obtained after sorting of intramuscularly transplanted muscles for SM/C2.6 and EGFP staining. The red box marks donor-derived satellite cells, which were then cultured after purification (shown in the center panel). Note that EGFP-positive cells express Pax7 (scale bars, $50 \mu \mathrm{m}$ ). The images in the bottom row show a single and nonintegrated DYS-HAC vector (arrowhead) in purified donor-derived satellite cells after FISH analysis (scale bar, $4 \mu \mathrm{m}$ ). Pictures are representative of data from a minimum of three independent experiments. 
Fig. 5. Intra-arterial delivery of corrected $\mathrm{mdx}$ mesoangioblasts in $\mathrm{SCID} / \mathrm{mdx}$ mice. (A) Whole-mount $\mathrm{X}$-gal staining showing donor mesoangioblasts associated with the femoral artery (arrowhead) and with small vessels 12 hours after injection (scale bar, $3 \mathrm{~mm}$ ). (B) X-gal plus $H \& E$ staining reveals donor cells in the interstitium and inside myofibers 12 hours after injection [bottomleft picture; scale bars, $100 \mu \mathrm{m}$ (upper) and $50 \mu \mathrm{m}$ (lower)]. (C) X-gal plus CD31 immunohistochemistry demonstrates extravasation of corrected mdx mesoangioblasts. (Upper panel) An X-gal-positive cell in the vessel wall. (Lower panel) A corrected $\mathrm{mdx}$ mesoangioblast that has just crossed the endothelial layer of a major vessel (scale bar, $30 \mu \mathrm{m}$ ). (D) Whole-mount X-gal staining of a tibialis anterior (TA) muscle $(n=6)$ showing the distribution of corrected mdx mesoangioblasts 36 hours after delivery in $\mathrm{SCID} / \mathrm{mdx}$ mice (scale bar, $1 \mathrm{~mm}$ ). (E) X-gal plus H\&E staining of sections from the tibialis anterior muscle in (D) [scale bars, $100 \mu \mathrm{m}$ (upper) and $50 \mu \mathrm{m}$ (lower)]. (F) Corrected mdx mesoangioblasts outside major and minor vessels. (G) Muscles containing EGFP-positive fibers 3 weeks after transplantation (scale bar, $400 \mu \mathrm{m}$ ). (H) Whole-mount staining showing X-gal-positive myofibers (4.5-fold enlargement) showing donor-derived nuclei in myofibers (scale bar, $0.5 \mathrm{~mm}$ ). (I) A cluster of fibers with donor-derived nuclei $(n=15)$ after X-gal and eosin staining (scale bar, $50 \mu \mathrm{m})$. (J) Immunofluorescence images showing dystrophin-positive fibers 3 weeks after transplantation. (Right images) Dystrophin-positive fibers containing $\beta$-gal-positive nuclei; $\beta$-gal/dystrophin double-positive fibers were difficult to identify because of cellular dispersion in the entire muscle [scale bars, $50 \mu \mathrm{m}$ (bottom left), $30 \mu \mathrm{m}$ (top right), and $20 \mu \mathrm{m}$ (bottom right)]. (K) RT-PCR showing expression of a muscle-specific (Dp427m) human

dystrophin isoform in treated muscles. Lane 1, differentiated corrected mdx mesoangioblasts; lane 2, treated SCID/mdx tibialis anterior muscle; lane 3, treated SCID/mdx gastrocnemius muscle; lane 4 , untreated SCID/mdx tibialis anterior muscle; lane 5, untreated SCID tibialis anterior muscle; lane 6, human skeletal muscle (positive control); lane 7, human brain (negative control). (L) Western blot showing dystrophin production in transplanted muscles (half of protein amount loaded for the SCID mouse control). (M) Quantification of donor cells and fibers in transplanted muscles at different time points. (N) Morphometric analysis of transplanted muscles, as described for Fig. 3F. (Left
A X-gal

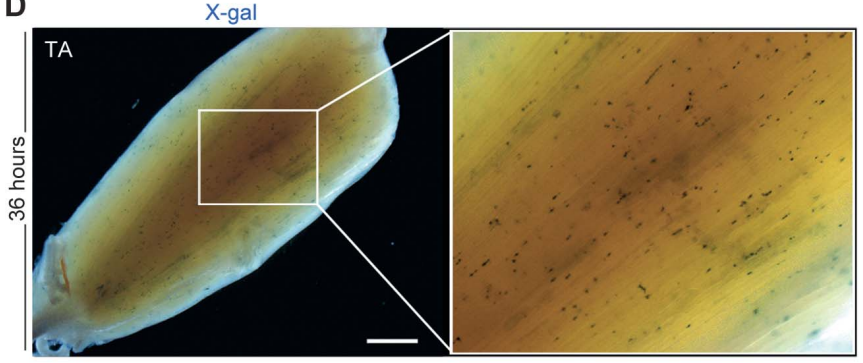

G

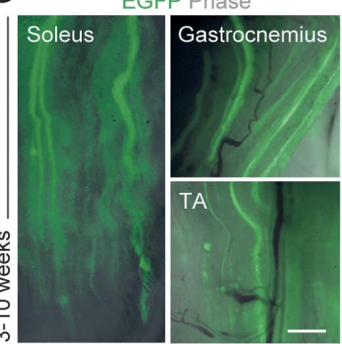

J

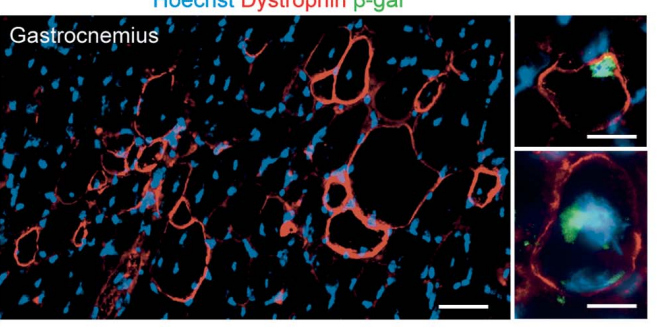

$\mathbf{N}$ $\begin{array}{ccc}\text { Treated } & \text { Untreated } & \text { Untreated } \\ \text { SCID/mdx } & \text { SCID/mdx } & \text { SCID }\end{array}$

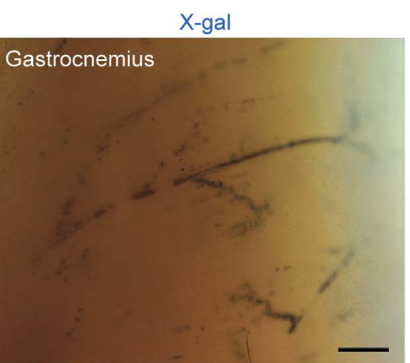

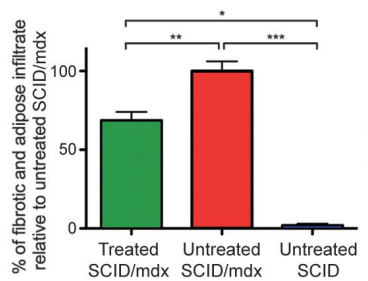

B

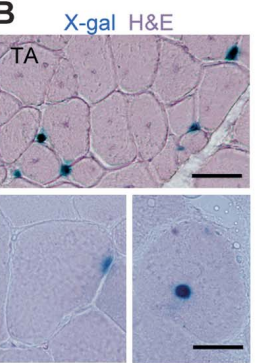

C X-gal CD31

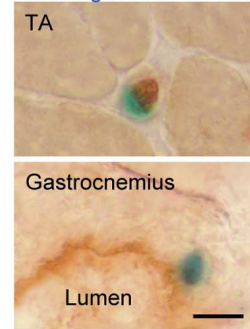

E
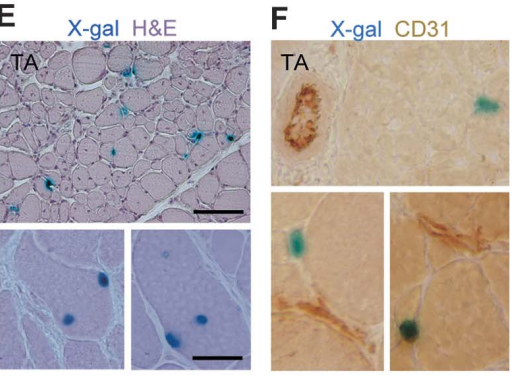

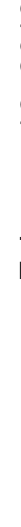

న

$\underset{\infty}{\infty}$

$\begin{array}{llllllllll}\text { K } & 1 & 2 & 3 & 4 & 5 & 6 & 7 & \mathbf{M}\end{array}$
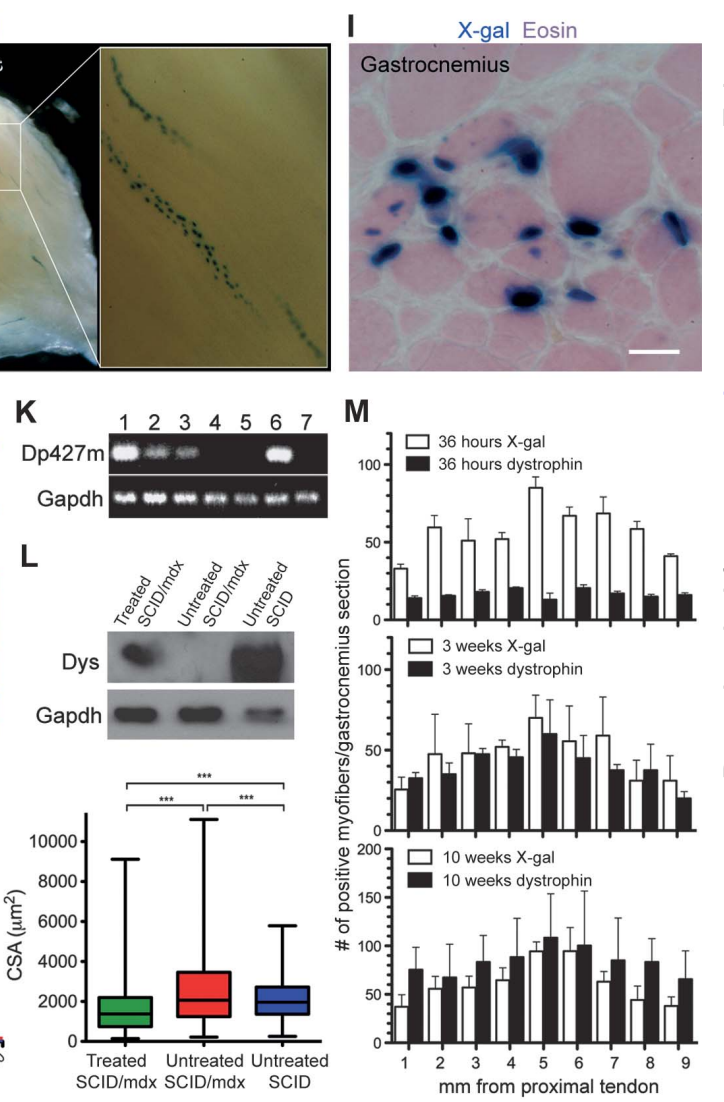

$\mathrm{mm}$ from proximal tendon

graph) Quantification of fibrosis in tibialis anterior muscle $\left(n=3 ;{ }^{*} P<0.05\right.$; ${ }^{* *} P<0.005$; ${ }^{* *} P<0.0005$, one-way ANOVA). (Central graph) Distribution of cross-sectional area (CSA) values for tibialis anterior muscle fibers (a minimum of 1000 myofibers per mouse with three mice per group) from treated, untreated SCID mdx mice, and untreated SCID mice. (Right graph) Box-and-whisker plot of the CSA data; significance between the groups assessed with one-way ANOVA and Bonferroni post test $(n=3 ; P<0.0005$ between treated and untreated dystrophic mice). Images are representative of a minimum of eight experiments. Error bars represent means \pm SEM. Additional details in fig. S3 and table S2. 
actively participate in muscle regeneration by crossing blood vessel walls after intra-arterial injection.

\section{Functional amelioration of the dystrophic phenotype in SCID/mdx mice}

To test whether muscles transplanted with corrected mdx mesoangioblasts showed functional amelioration, we measured motor capacity, myofiber fragility, and specific force in treated and untreated SCID/mdx mice. Motor capacity was assessed using a treadmill test to exhaustion, which measures whole endurance capacity. This test had previously been shown to detect amelioration of symptoms in $\mathrm{mdx}$ and SCID/mdx mice after cell or gene therapy $(33,37)$. Both intramuscularly and intraarterially transplanted mice showed statistically significant enhanced motor capacity after treatment (Fig. 6, A and B, and video S1), with mice running from 50 to $80 \%$ more than untreated animals (normalizing performances with their baseline values; Fig. 6A).

Additionally, upon systemic administration of Evans blue dye (EBD) (38), intramuscularly and intra-arterially transplanted muscles showed threefold fewer fibers staining with this dye (which permeates damaged muscle fibers) than did untreated SCID/mdx mice (Fig. 6C). EGFPpositive fibers always stained negative with $\mathrm{EBD}$, indicating that dystrophin expression from the DYS-HAC vector prevented membrane fragility and subsequent permeability to this dye.

The increase in motor capacity of the treated mice analyzed using the treadmill assay was confirmed by a freewheel running test, which was known to detect amelioration of symptoms in dystrophic mice after treatment (39). Both intramuscularly and intra-arterially treated $\mathrm{SCID} / \mathrm{mdx}$ mice ran four- and twofold, respectively, more than vehicleinjected control animals, demonstrating enhanced voluntary motor capacity (Fig. 6D; $n=9$ for intramuscularly treated SCID/mdx mice, $n=7$ for intra-arterially treated SCID/mdx mice, $n=13$ for untreated SCID/mice, $n=13$ for control nondystrophic SCID mice; $P<0.05$, one-way ANOVA and Bonferroni post test). Notably, the effect was still evident several months after treatment.

To assess whether the observed rescue of dystrophin expression correlated with the ability to generate force by whole muscles, we measured normalized tetanic force of isolated tibialis anterior muscles from intramuscularly transplanted mice. We found a persistent increase in force after treatment $(8$ months after transplantation; Fig. $6 \mathrm{E} ; 20$ tibialis anterior muscles analyzed; $P<0.05$, one-way ANOVA and Bonferroni post test). In the case of intra-arterial injection of corrected mdx mesoangioblasts, despite clear amelioration of motor defects by functional testing, the specific tetanic force of tibialis anterior muscles was not significantly different from that in untreated mice $(n=6 ; P>0.05)$. This result may be due to the widespread distribution of donor cells in downstream muscles after a single injection in the femoral artery (fig. S3), resulting in lower numbers in the single muscle analyzed. The impact of dystrophin expression on function was also studied on single skinned tibialis anterior myofibers (Fig. 6E). Each myofiber was analyzed for specific force, fiber type, and dystrophin expression with an approach that was used successfully previously (11). The data indicate an increase in force in dystrophinpositive fibers $(n=36)$ compared to dystrophin-negative $(n=33)$ or partially positive fibers $(n=31)$ in the same muscle (Fig. 6E; $P<0.05$, one-way ANOVA and Bonferroni post test).

Finally, to test therapeutic efficacy in a more severe dystrophic model, we transplanted corrected mdx mesoangioblasts into immunosuppressed Sgca-null mice. We observed enhancement of motor capacity and a reduced uptake of EBD (fig. S4; $P<0.0005$ and $P<0.005$, respectively, one-way ANOVA; a minimum of three mice per group). Conversely, transplantation of uncorrected mdx mesoangioblasts into SCID/mdx mice did not elicit significant amelioration of the dystrophic phenotype (fig. S5), although modest benefits were observed possibly due to a paracrine effect. Collectively, these results demonstrate that engraftment of corrected mdx mesoangioblasts into SCID/mdx mice and their differentiation into myofibers with a contribution to the muscle satellite cell pool led to morphological and functional amelioration of the dystrophic phenotype in these animals.

\section{DISCUSSION}

Here, we provide evidence for effective stem cell-mediated gene replacement therapy with a HAC in dystrophic mice. Transfer of the large human dystrophin gene into mesoangioblasts from $\mathrm{mdx}$ mice resulted in genetically corrected cells that proliferated, differentiated, and expressed surface markers in a manner reminiscent of that of the parental population. Corrected mdx mesoangioblasts robustly engrafted in the dystrophic skeletal muscles of SCID/mdx mice and stably produced human dystrophin, resulting in morphological and functional amelioration of the dystrophic phenotype.

To optimize muscle differentiation of corrected $\mathrm{mdx}$ mesoangioblasts, we transduced these cells with a lentiviral vector expressing MyoD that enhanced myogenesis without interfering with proliferation or migration. This extra step eliminated the variability in spontaneous myogenic potency that was observed among different mesoangioblast populations isolated from mouse (8), human (13), and canine (11) preand postnatal tissues. This strategy also reintroduced myogenic potential to these cells, which might have lost their capacity for differentiation into muscle cells during MMCT in high-density culture. Moreover, because MyoD is an anti-oncogene (40), its expression guarantees an additional layer of safety for the use of mesoangioblasts in cell therapy. Unexpectedly, the detection of donor-derived satellite cells showed that MyoD overexpression does not interfere with self-renewal of mesoangioblasts and their recruitment into the muscle satellite cell niche, possibly because Pax7 prevents differentiation by affecting MyoD protein stability (41). Given that this mechanism is independent of transcription, it may also operate in cells overexpressing MyoD, with the Pax7/MyoD expression ratio likely to be regulated by extracellular cues that dictate cell fate (41). Our data support this observation and indicate that cells that expressed MyoD for at least a few cell cycles may return to quiescence and reexpress $\mathrm{Pax} 7$ in vivo.

Transplantation of SCID/mdx mice with corrected mdx mesoangioblasts reduced myofiber fragility and increased exercise tolerance by more than $50 \%$. Intramuscular transplantation resulted in about $10 \%$ of myofibers becoming dystrophin positive, which resulted in production of dystrophin at $20 \%$ of the levels found in wild-type SCID mice, which possibly may reflect increased dystrophin synthesis in donor cell nuclei. The increase in dystrophin ameliorated dystrophic signs and improved muscle function up to 8 months after transplantation. For intra-arterial transplantation, the uniform dispersal of corrected mdx mesoangioblasts in large muscle units provided a similar result. However, scaling down the dosage to one-third the number of cells transplanted resulted in failure to enhance motor capacity, confirming that under these conditions, $10^{6}$ cells injected into the femoral artery was the effective dose (fig. S6). Together, these data are consistent with reports 
Fig. 6. Functional amelioration of the dystrophic phenotype in SCID/mdx mice transplanted with DYS-HAC-corrected mdx mesoangioblasts. (A) Time to exhaustion in treadmill tests of untreated SCID control mice and treated and untreated SCID/mdx mice. Exercise tolerance was higher in intramuscularly (IM; left graph; $n=13$ ) and intra-arterially (IA; right graph; $n=10$ ) injected SCID/mdx mice compared with untreated animals ( $n=9$ and 8, respectively). Average motor capacity relative to baseline performances (measured until the day before first transplantation) for the intramuscularly injected transplant group from days 10 to 130 was $177.2 \%$ for treated $\mathrm{SCID} / \mathrm{mdx}$ mice (green line), $95 \%$ for untreated SCID/mdx mice (red line), and $108.3 \%$ for untreated SCID mice (blue line). From days 250 to 270 , motor capacity was $85 \%$ for treated $\mathrm{SCID} / \mathrm{mdx}$ mice, 33\% for untreated SCID/mdx mice, and $90.6 \%$ for untreated SCID mice. Average relative motor capacity relative to baseline for the intra-arterially injected group (days 10 to 70 ) was $165.9 \%$ for treated SCID/mdx mice, $111.1 \%$ for untreated $\mathrm{SCID} / \mathrm{mdx}$ mice, and $103.7 \%$ for untreated SCID mice. All control mice received PBS injections (vehicle control). (B) The two graphs show absolute values of the treadmill test presented in (A). For the intramuscular transplant group, the values used are those from days 10 to 130, and for the intra-arterial transplant group, the values are from days 10 to 70. (C) Evans blue dye (EBD) uptake assay for muscles in mice after exhaustion on the treadmill test. The upper panel contains fluorescent stereoscopic images of tibialis anterior (TA) muscles taken at exhaustion (after nine treadmill test measurements were taken). Images show less EBD fluorescence in the treated muscle and no EGFP-EBD colocalization (scale bar, $2 \mathrm{~mm}$ ). Dashed lines mark the level of the sections indicated by the arrows (scale bar, $1 \mathrm{~mm}$ ). Transversal sections show less EBD-positive fibers in treated versus untreated muscles. The two bottom left pictures (top: transversal intramuscularly injected tibialis anterior muscle; center: longitudinal section from intra-arterially injected gastrocnemius muscle) demonstrate no colocalization between red and green staining fibers; the bottom image shows X-gal plus H\&E staining of a serial section (scale bars, $100 \mu \mathrm{m}$ ). The graphs quantify the assay for intramuscularly injected tibialis anterior muscle (as described for the top panel) and tibialis anterior muscle from intra-arterially injected mice [at day 30 in (A), after treadmill measurements] and show fewer EBD-positive fibers in the treated tibialis anterior muscle sections at different craniocaudal levels. (D) Graphs quantifying the average distance run on a freewheel by SCID/mdx mice ( $n=16$ treated mice) at the end of the treadmill tests shown in (A). The intramuscular transplant group performance is reduced compared to that for the intra-arterial transplant
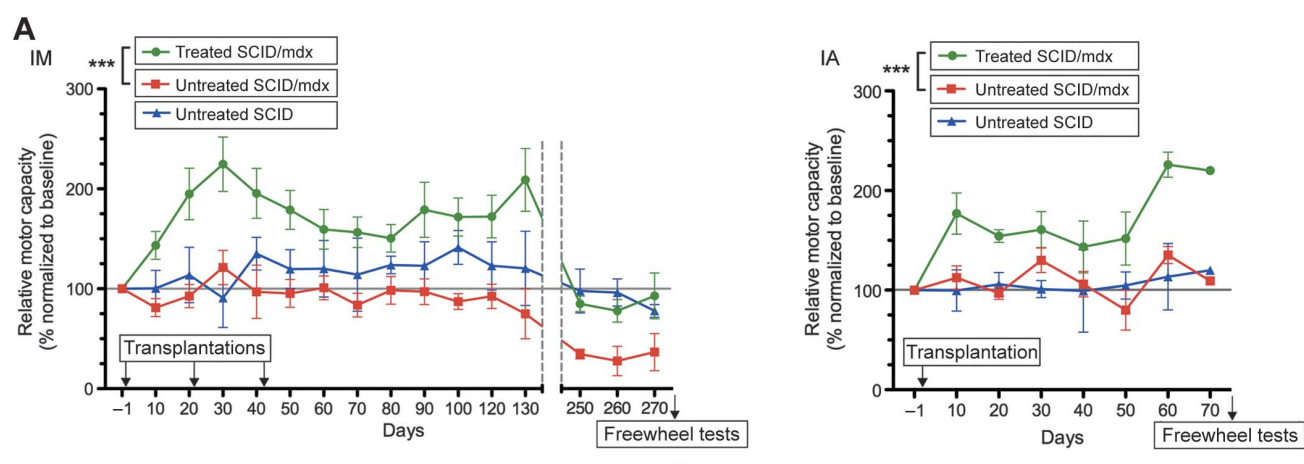

B
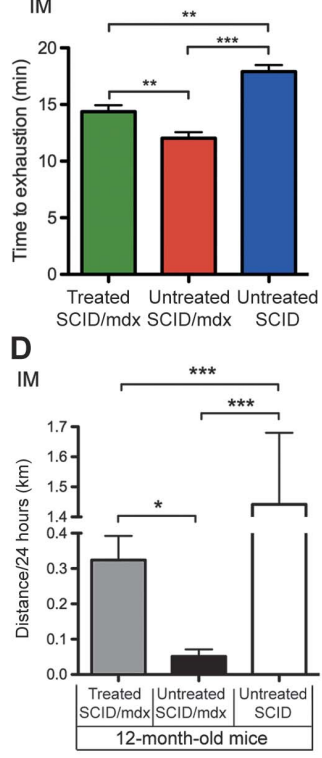

E

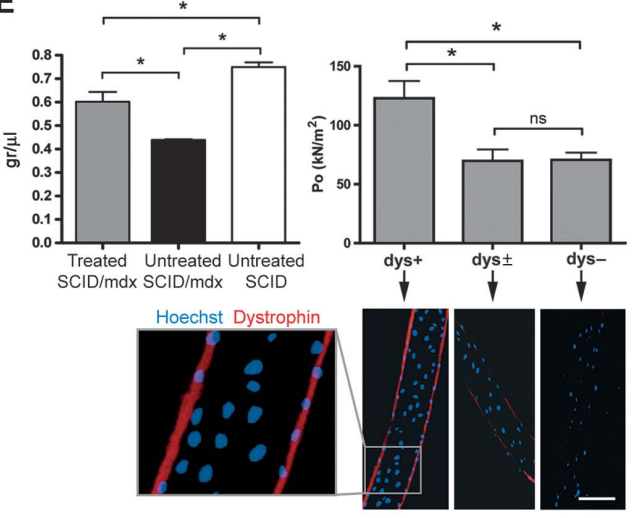

C

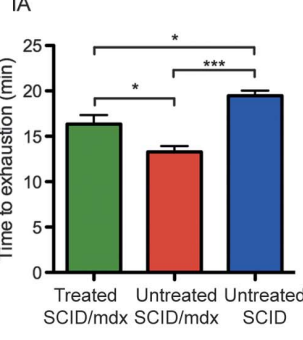

IA

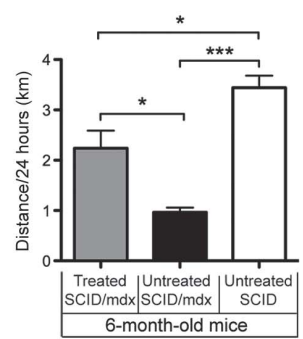

Treated SCID/mdx Untreated SCID/mdx

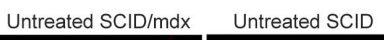

group because of the old age of the mice. (E) Force measurements of transplanted muscles (details in the Supplementary Material). (Left graph) Normalized tetanic force of isolated tibialis anterior muscles ( $n \geq 7$ per group) from intramuscular transplant mice. (Right graph) Mean values of specific force for a population of 100 single myofibers dissected from tibialis anterior muscles injected intramuscularly with corrected $\mathrm{mdx}$ mesoangioblasts. Myofibers were grouped into dystrophin-positive (dys+; $n=36)$, dystrophin partly positive (dys $\pm ; n=31$ ), and dystrophin-negative (dys-; $n=33$ ) based on immunostaining after force determination (examples in the bottom row; scale bar, $30 \mu \mathrm{m})$. Additional data in figs. S4 and S5. Error bars represent means \pm SEM. ${ }^{*} P<0.005$; ${ }^{* *} P<0.005$; ${ }^{* * *} P<0.0005$, one-way ANOVA. ns, not significant. 
indicating that dystrophin production as low as $30 \%$ of that found in healthy animals or individuals prevents muscular dystrophy in mice (42) and humans (43). Our data are also in agreement with a recent report showing amelioration of dystrophic characteristics in muscle with low dystrophin expression ( $\leq 10 \%$ of wild type), principally due to the pleiotropic beneficial effects of dystrophin on the regulation of different microRNAs involved in oxidative stress and fibrosis (44).

In summary, our strategy results in correction of the dystrophic phenotype that is comparable to that previously obtained with wildtype mesoangioblasts (10). Our approach would not require immunosuppression in a clinical setting, especially if the new generation of DYS-HAC vectors were to be used; these vectors would be devoid of immunogenic transgenes such as EGFP. The possibility that autologous gene or cell therapy may require some immunosuppression is currently under investigation. However, further experiments are required to address this point because the presence of peripheral $\mathrm{T}$ cells directed against endogenous dystrophin, but apparently unable to eliminate revertant fibers, has been reported (23). Transfer of HAC vectors into dystrophic mesoangioblasts may provide several important advantages compared with other gene and cell therapy strategies. These include (i) eligibility of all patients independent of the type of dystrophin mutation they carry (19); (ii) avoidance of the need for long-term immunosuppression; (iii) the presence of the entire dystrophin gene locus with correctly regulated expression of the different transcripts (including copy number control and absence of positional effect); (iv) no limit on the size of the genes or cDNAs that could be accommodated in the HAC, thus providing the potential for achieving regulated expression of additional genes with beneficial effects such as those encoding MyoD or insulin-like growth factor 1 ; (v) improved safety compared with integrating vectors due to the episomal nature of HACs and their elimination by HSV-TK (45); or (vi) centromere inactivation if needed (46). On the other hand, human mesoangioblasts will require an additional step to extend their proliferative capability and to ensure that they survive selection after HAC transfer, as has been already discovered for human mesenchymal stem cells (25). To achieve this, we are developing a platform for engineering mesoangioblasts from DMD patients containing excisable lentiviral vectors expressing immortalizing genes in a reversible fashion.

Currently, several different therapies for DMD are being tested at the preclinical level and some are undergoing clinical experimentation (6). Some trials have not yielded positive results, for example, those using PTC124 (22) or adeno-associated vectors carrying minidystrophin (23). So far, only exon skipping seems to have some efficacy in DMD patients $(20,21)$. Even in this case, about one-fourth of DMD mutations cannot be corrected with exon skipping (19). In the future, patients with these mutations may benefit from stem cell-mediated transfer of the entire dystrophin locus using a HAC vector, once technical hurdles and regulatory issues are solved.

\section{MATERIALS AND METHODS}

\section{Cell cultures and MMCT}

Mesoangioblasts were isolated from mdx mouse and maintained in culture as described previously (47). MyoD-expressing mdx(DYS-HAC) MABs (DYS-HAC-corrected mdx mesoangioblasts) were maintained in culture in Dulbecco's modified Eagle's medium (DMEM) (Sigma) containing 20\% fetal bovine serum (FBS) (EuroClone) and basic fibroblast growth factor (bFGF) (5 ng/ml) (Invitrogen). C2C12 myoblasts were cultured as already described (47). DYS-HAC was constructed from a HAC backbone named 21HAC2 (45). Mesoangioblast hybrids containing the DYS-HAC were produced by MMCT from two donor Chinese hamster ovary $(\mathrm{CHO})$ cells containing DYS-HAC and maintained in culture with blasticidin $(5 \mu \mathrm{g} / \mathrm{ml})$ (Sigma). Briefly, $4 \times 10^{6} \mathrm{mdxMABs}(\mathrm{mdx}$ mesoangioblasts) were fused with microcells prepared from $\mathrm{CHO}$ (DYS-HAC) and selected with blasticidin, and then each DYS-HAC line was examined by PCR and FISH analyses as previously described (25).

\section{Mice}

Mice were housed in Charles River Laboratories and/or at San Raffaele Scientific Institute animal house. They were kept in specific pathogenfree conditions, and all procedures conformed to Italian law and were approved by the San Raffaele Animal Care and Use Committee.

\section{Mesoangioblast transplantation}

Four- to 5-month-old exercised mice were used for experiments. Intramuscular delivery ( $n=124$ muscles; $24 \mathrm{SCID} /$ mice) was done by injecting $10^{6} \mathrm{mdx}$ (DYS-HAC)MABs into tibialis anterior and/or gastrocnemius and quadriceps muscles. Most transplantations were done by injecting the muscles three times every 3 weeks. For intra-arterial delivery $[n=$ 25 intrafemoral injections of mdx(DYS-HAC)MAB in fifteen 5-monthold SCID/mdx], mice were anesthetized with Avertin (Sigma) and $10^{6}$ $\mathrm{mdx}$ (DYS-HAC)MABs were diluted in $50 \mu \mathrm{l}$ of phosphate-buffered saline (PBS) and injected into the isolated femoral artery (fig. S3A).

\section{Immunofluorescence}

Cells and tissues were processed as already published (10) and incubated overnight at $4^{\circ} \mathrm{C}$ with the primary and secondary antibodies listed in the Supplementary Material. The sections for mouse anti-Pax7 immunostaining were pretreated in boiling sodium citrate buffer.

\section{Histology and histochemistry}

Tissue sections were stained with hematoxylin and eosin (H\&E) (Sigma), $\mathrm{X}$-gal (Invitrogen), and Masson trichrome (Bio-Optica) according to standard protocols. For dystrophin and Sgca immunohistochemistry, cryosections were processed as described in the Supplementary Material and the secondary antibodies (Dako) used were horseradish peroxidase (HRP)-conjugated or biotinylated. Signal was detected with DAB (Sigma) and an ABC kit (Vector Laboratories Inc.).

\section{PCR, RT-PCR, and Western blot}

We performed PCRs and RT-PCRs using primers and conditions previously published and detailed in the Supplementary Material together with the Western blot assay.

\section{Functional assays}

To measure exercise tolerance, we tested 5-month-old control untransplanted SCID ( $n=9$ for intramuscular; $n=8$ for intra-arterial), untransplanted SCID/mdx ( $n=9$ for intramuscular; $n=8$ for intraarterial), and transplanted SCID/mdx mice $(n=14$ for intramuscular; $n=15$ for intra-arterial) on a treadmill (Columbus Instruments). Mice were trained to the procedure for 1 week, and the speed was increased $2 \mathrm{~m} / \mathrm{min}$ every 2 min until exhaustion.

To measure voluntary motor capacity, we subjected treated SCID/mdx mice ( $n=9$ for intramuscular; $n=7$ for intra-arterial), untreated SCID/mice ( $n=8$ for intramuscular; $n=5$ for intra-arterial), and control SCID mice 
( $n=7$ for intramuscular; $n=5$ for intra-arterial) to measurements of the total distance run for 24 hours on a freewheel. Each mouse was trained to the procedure twice, and performances were measured three times with the appropriate control mice.

EBD uptake assay was done as already described (38). Briefly, $30 \mathrm{~min}$ after the last treadmill, EBD ( $5 \mathrm{mg} / \mathrm{ml}$; Sigma) was injected through the tail vein. Mice (intramuscular: $n=6$ treated SCID $/ \mathrm{mdx}, n=6$ untreated SCID $/ \mathrm{mdx}, n=5$ treated SCID; intra-arterial: $n=5$ treated SCID $/ \mathrm{mdx}, n=5$ untreated SCID/mdx, $n=4$ treated SCID) were killed 24 hours after injection, and muscles were analyzed under a fluorescence stereomicroscope.

Specific force of single skinned myofibers ( $n=100$; dystrophin staining classified in positive, patched, and negative) was determined as previously published $(10,11)$. Mechanical analysis of intact muscles is available in the Supplementary Material.

\section{Statistical analysis}

Data were analyzed with Microsoft Excel 12.1 and GraphPad Prism 5. We expressed values as means \pm SE. We assessed significance of the differences between means by one- or two-way ANOVA followed by Bonferroni test. A probability of less than 5\% $(P<0.05)$ was considered to be statistically significant.

\section{SUPPLEMENTARY MATERIAL}

www.sciencetranslationalmedicine.org/cgi/content/full/3/96/96ra78/DC1

Materials and Methods

Fig. S1. Telomerase activity assay of $\mathrm{mdx}(\mathrm{DYS}-\mathrm{HAC}) \mathrm{MABs}$ by telomeric repeat amplification protocol (TRAP).

Fig. S2. Engraftment and differentiation of $m d x$ (DYS-HAC)MABs upon intramuscular transplantation in SCID/mdx mice.

Fig. S3. Intra-arterial transplantation and skeletal muscle engraftment of mdx(DYS-HAC)MABs. Fig. S4. Transplantation of mdx(DYS-HAC)MABs in immunosuppressed Sgca-null mice. Fig. S5. Transplantation of mdxMABs not containing the DYS-HAC vector. Fig. S6. Functional outcome of low-dose mdx(DYS-HAC)MAB transplantation. Table S1. Summary of all intramuscular and intra-arterial transplantations of mdxMABs. Table S2. Morphometric analysis of muscles transplanted with mdx(DYS-HAC)MAB. Video S1. Improved motor capacity of $\mathrm{mdx}$ (DYS-HAC)MAB-transplanted SCID/mdx mice. References

\section{REFERENCES AND NOTES}

1. E. P. Hoffman, R. H. Brown Jr., L. M. Kunkel, Dystrophin: The protein product of the Duchenne muscular dystrophy locus. Cell 51, 919-928 (1987).

2. M. Koenig, E. P. Hoffman, C. J. Bertelson, A. P. Monaco, C. Feener, L. M. Kunkel, Complete cloning of the Duchenne muscular dystrophy (DMD) CDNA and preliminary genomic organization of the DMD gene in normal and affected individuals. Cell 50, 509-517 (1987).

3. A. E. Emery, The muscular dystrophies. Lancet 359, 687-695 (2002).

4. A. E. Emery, F. Muntoni, Duchenne Muscular Dystrophy (Oxford Univ. Press, Oxford, UK, ed. 3, 2003).

5. F. S. Tedesco, A. Dellavalle, J. Diaz-Manera, G. Messina, G. Cossu, Repairing skeletal muscle: Regenerative potential of skeletal muscle stem cells. J. Clin. Invest. 120, 11-19 (2010).

6. A. Goyenvalle, J. T. Seto, K. E. Davies, J. Chamberlain, Therapeutic approaches to muscular dystrophy. Hum. Mol. Genet. 20, R69-R78 (2011).

7. F. Muntoni, S. Torelli, A. Ferlini, Dystrophin and mutations: One gene, several proteins, multiple phenotypes. Lancet Neurol. 2, 731-740 (2003).

8. M. G. Minasi, M. Riminucci, L. De Angelis, U. Borello, B. Berarducci, A. Innocenzi, A. Caprioli, D. Sirabella, M. Baiocchi, R. De Maria, R. Boratto, T. Jaffredo, V. Broccoli, P. Bianco, G. Cossu, The meso-angioblast: A multipotent, self-renewing cell that originates from the dorsal aorta and differentiates into most mesodermal tissues. Development 129, 2773-2783 (2002).
9. C. Gargioli, M. Coletta, F. De Grandis, S. M. Cannata, G. Cossu, PIGF-MMP-9-expressing cells restore microcirculation and efficacy of cell therapy in aged dystrophic muscle. Nat. Med. 14, 973-978 (2008).

10. M. Sampaolesi, Y. Torrente, A. Innocenzi, R. Tonlorenzi, G. D’Antona, M. A. Pellegrino, R. Barresi, N. Bresolin, M. G. De Angelis, K. P. Campbell, R. Bottinelli, G. Cossu, Cell therapy of $\alpha$-sarcoglycan null dystrophic mice through intra-arterial delivery of mesoangioblasts. Science 301, 487-492 (2003).

11. M. Sampaolesi, S. Blot, G. D'Antona, N. Granger, R. Tonlorenzi, A. Innocenzi, P. Mognol, J. L. Thibaud, B. G. Galvez, I. Barthélémy, L. Perani, S. Mantero, M. Guttinger, O. Pansarasa, C. Rinaldi, M. G. Cusella De Angelis, Y. Torrente, C. Bordignon, R. Bottinelli, G. Cossu, Mesoangioblast stem cells ameliorate muscle function in dystrophic dogs. Nature $\mathbf{4 4 4}$ 574-579 (2006)

12. S. Tajbakhsh, Skeletal muscle stem cells in developmental versus regenerative myogenesis. J. Intern. Med. 266, 372-389 (2009).

13. A. Dellavalle, M. Sampaolesi, R. Tonlorenzi, E. Tagliafico, B. Sacchetti, L. Perani, A. Innocenzi, B. G. Galvez, G. Messina, R. Morosetti, S. Li, M. Belicchi, G. Peretti, J. S. Chamberlain, W. E. Wright, Y. Torrente, S. Ferrari, P. Bianco, G. Cossu, Pericytes of human skeletal muscle are myogenic precursors distinct from satellite cells. Nat. Cell Biol. 9, 255-267 (2007).

14. A. L. Arnett, J. R. Chamberlain, J. S. Chamberlain, Therapy for neuromuscular disorders. Curr. Opin. Genet. Dev. 19, 290-297 (2009).

15. E. Kimura, S. Li, P. Gregorevic, B. M. Fall, J. S. Chamberlain, Dystrophin delivery to muscles of $m d x$ mice using lentiviral vectors leads to myogenic progenitor targeting and stable gene expression. Mol. Ther. 18, 206-213 (2010).

16. P. Gregorevic, M. J. Blankinship, J. M. Allen, J. S. Chamberlain, Systemic microdystrophin gene delivery improves skeletal muscle structure and function in old dystrophic $m d x$ mice. Mol. Ther. 16, 657-664 (2008).

17. R. C. Hirst, K. J. McCullagh, K. E. Davies, Utrophin upregulation in Duchenne muscular dystrophy. Acta Myol. 24, 209-216 (2005).

18. Q. L. Lu, T. Yokota, S. Takeda, L. Garcia, F. Muntoni, T. Partridge, The status of exon skipping as a therapeutic approach to Duchenne muscular dystrophy. Mol. Ther. 19, 9-15 (2011).

19. A. Aartsma-Rus, I. Fokkema, J. Verschuuren, I. Ginjaar, J. van Deutekom, G. J. van Ommen, J. T. den Dunnen, Theoretic applicability of antisense-mediated exon skipping for Duchenne muscular dystrophy mutations. Hum. Mutat. 30, 293-299 (2009).

20. N. M. Goemans, M. Tulinius, J. T. van den Akker, B. E. Burm, P. F. Ekhart, N. Heuvelmans, T. Holling, A. A. Janson, G. J. Platenburg, J. A. Sipkens, J. M. Sitsen, A. Aartsma-Rus, G. J. van Ommen, G. Buyse, N. Darin, J. J. Verschuuren, G. V. Campion, S. J. de Kimpe, J. C. van Deutekom, Systemic administration of PRO051 in Duchenne's muscular dystrophy. N. Engl. J. Med. 364, 1513-1522 (2011).

21. M. Kinali, V. Arechavala-Gomeza, L. Feng, S. Cirak, D. Hunt, C. Adkin, M. Guglieri, E. Ashton, S. Abbs, P. Nihoyannopoulos, M. E. Garralda, M. Rutherford, C. McCulley, L. Popplewell, I. R. Graham, G. Dickson, M. J. Wood, D. J. Wells, S. D. Wilton, R. Kole, V. Straub, K. Bushby, C. Sewry, J. E. Morgan, F. Muntoni, Local restoration of dystrophin expression with the morpholino oligomer AVl-4658 in Duchenne muscular dystrophy: A single-blind, placebo-controlled, dose-escalation, proofof-concept study. Lancet Neurol. 8, 918-928 (2009).

22. R. S. Finkel, Read-through strategies for suppression of nonsense mutations in Duchenne/Becker muscular dystrophy: Aminoglycosides and ataluren (PTC124). J. Child Neurol. 25, 1158-1164 (2010).

23. J. R. Mendell, K. Campbell, L. Rodino-Klapac, Z. Sahenk, C. Shilling, S. Lewis, D. Bowles, S. Gray, C. Li, G. Galloway, V. Malik, B. Coley, K. R. Clark, J. Li, X. Xiao, J. Samulski, S. W. McPhee, R. J. Samulski, C. M. Walker, Dystrophin immunity in Duchenne's muscular dystrophy. N. Engl. J. Med. 363, 1429-1437 (2010).

24. Y. Kazuki, M. Oshimura, Human artificial chromosomes for gene delivery and the development of animal models. Mol. Ther. 10.1038/mt.2011.136 (2011).

25. H. Hoshiya, Y. Kazuki, S. Abe, M. Takiguchi, N. Kajitani, Y. Watanabe, T. Yoshino, Y. Shirayoshi, K. Higaki, G. Messina, G. Cossu, M. Oshimura, A highly stable and nonintegrated human artificial chromosome ( $\mathrm{HAC}$ ) containing the $2.4 \mathrm{Mb}$ entire human dystrophin gene. Mol. Ther. 17, 309-317 (2009).

26. Y. Kazuki, M. Hiratsuka, M. Takiguchi, M. Osaki, N. Kajitani, H. Hoshiya, K. Hiramatsu, T. Yoshino, K. Kazuki, C. Ishihara, S. Takehara, K. Higaki, M. Nakagawa, K. Takahashi, S. Yamanaka, M. Oshimura, Complete genetic correction of iPS cells from Duchenne muscular dystrophy. Mol. Ther. 18, 386-393 (2010).

27. M. A. Mandegar, D. Moralli, S. Khoja, S. Cowley, D. Y. Chan, M. Yusuf, S. Mukherjee, M. P. Blundell, E. V. Volpi, A. J. Thrasher, W. James, Z. L. Monaco, Functional human artificial chromosomes are generated and stably maintained in human embryonic stem cells. Hum. Mol. Genet. 20, 2905-2913 (2011).

28. J. J. Harrington, G. Van Bokkelen, R. W. Mays, K. Gustashaw, H. F. Willard, Formation of de novo centromeres and construction of first-generation human artificial microchromosomes. Nat. Genet. 15, 345-355 (1997).

29. G. Bulfield, W. G. Siller, P. A. Wight, K. J. Moore, X chromosome-linked muscular dystrophy $(m d x)$ in the mouse. Proc. Natl. Acad. Sci. U.S.A. 81, 1189-1192 (1984).

30. Y. Katakura, S. Alam, S. Shirahata, Immortalization by gene transfection. Methods Cell Biol. 57, 69-91 (1998). 
31. R. L. Davis, H. Weintraub, A. B. Lassar, Expression of a single transfected cDNA converts fibroblasts to myoblasts. Cell 51, 987-1000 (1987).

32. B. W. Schäfer, B. T. Blakely, G. J. Darlington, H. M. Blau, Effect of cell history on response to helix-loop-helix family of myogenic regulators. Nature 344, 454-458 (1990).

33. R. Benchaouir, M. Meregalli, A. Farini, G. D’Antona, M. Belicchi, A. Goyenvalle, M. Battistelli, N. Bresolin, R. Bottinelli, L. Garcia, Y. Torrente, Restoration of human dystrophin following transplantation of exon-skipping-engineered DMD patient stem cells into dystrophic mice. Cell Stem Cell 1, 646-657 (2007).

34. M. Sandri, M. Podhorska-Okolow, V. Geromel, C. Rizzi, P. Arslan, C. Franceschi, U. Carraro, Exercise induces myonuclear ubiquitination and apoptosis in dystrophin-deficient muscle of mice. J. Neuropathol. Exp. Neurol. 56, 45-57 (1997).

35. T. Saito, Y. Yamamoto, T. Matsumura, H. Fujimura, S. Shinno, Serum levels of vascular endothelial growth factor elevated in patients with muscular dystrophy. Brain Dev. 31 612-617 (2009).

36. S. B. Chargé, M. A. Rudnicki, Cellular and molecular regulation of muscle regeneration. Physiol. Rev. 84, 209-238 (2004).

37. M. A. Denti, A. Rosa, G. D'Antona, O. Sthandier, F. G. De Angelis, C. Nicoletti, M. Allocca, O. Pansarasa, V. Parente, A. Musarò, A. Auricchio, R. Bottinelli, I. Bozzoni, Body-wide gene therapy of Duchenne muscular dystrophy in the $m d x$ mouse model. Proc. Natl. Acad. Sci. U.S.A. 103, 3758-3763 (2006).

38. C. I. Wooddell, G. Zhang, J. B. Griffin, J. O. Hegge, T. Huss, J. A. Wolff, Use of Evans blue dye to compare limb muscles in exercised young and old $m d x$ mice. Muscle Nerve 41, 487-499 (2010).

39. S. Brunelli, C. Sciorati, G. D’Antona, A. Innocenzi, D. Covarello, B. G. Galvez, C. Perrotta, A. Monopoli, F. Sanvito, R. Bottinelli, E. Ongini, G. Cossu, E. Clementi, Nitric oxide release combined with nonsteroidal antiinflammatory activity prevents muscular dystrophy pathology and enhances stem cell therapy. Proc. Natl. Acad. Sci. U.S.A. 104, 264-269 (2007).

40. O. Halevy, B. G. Novitch, D. B. Spicer, S. X. Skapek, J. Rhee, G. J. Hannon, D. Beach, A. B. Lassar, Correlation of terminal cell cycle arrest of skeletal muscle with induction of p21 by MyoD. Science 267, 1018-1021 (1995).

41. H. C. Olguin, Z. Yang, S. J. Tapscott, B. B. Olwin, Reciprocal inhibition between Pax7 and muscle regulatory factors modulates myogenic cell fate determination. J. Cell Biol. 177, 769-779 (2007).

42. D. J. Wells, K. E. Wells, E. A. Asante, G. Turner, Y. Sunada, K. P. Campbell, F. S. Walsh, G. Dickson, Expression of human full-length and minidystrophin in transgenic $m d x$ mice: Implications for gene therapy of Duchenne muscular dystrophy. Hum. Mol. Genet. 4, 1245-1250 (1995).

43. M. Neri, S. Torelli, S. Brown, I. Ugo, P. Sabatelli, L. Merlini, P. Spitali, P. Rimessi, F. Gualandi, C. Sewry, A. Ferlini, F. Muntoni, Dystrophin levels as low as $30 \%$ are sufficient to avoid muscular dystrophy in the human. Neuromuscul. Disord. 17, 913-918 (2007).

44. D. Cacchiarelli, J. Martone, E. Girardi, M. Cesana, T. Incitti, M. Morlando, C. Nicoletti, T. Santini, O. Sthandier, L. Barberi, A. Auricchio, A. Musarò, I. Bozzoni, MicroRNAs involved in molecular circuitries relevant for the Duchenne muscular dystrophy pathogenesis are controlled by the dystrophin/nNOS pathway. Cell Metab. 12, 341-351 (2010).

45. Y. Kazuki, H. Hoshiya, M. Takiguchi, S. Abe, Y. lida, M. Osaki, M. Katoh, M. Hiratsuka, Y. Shirayoshi, K. Hiramatsu, E. Ueno, N. Kajitani, T. Yoshino, K. Kazuki, C. Ishihara, S. Takehara, S. Tsuji, F. Ejima, A. Toyoda, Y. Sakaki, V. Larionov, N. Kouprina, M. Oshimura, Refined human artificial chromosome vectors for gene therapy and animal transgenesis. Gene Ther. 18, 384-393 (2011).

46. Y. lida, J. H. Kim, Y. Kazuki, H. Hoshiya, M. Takiguchi, M. Hayashi, I. Erliandri, H. S. Lee, A. Samoshkin, H. Masumoto, W. C. Earnshaw, N. Kouprina, V. Larionov, M. Oshimura, Human artificial chromosome with a conditional centromere for gene delivery and gene expression. DNA Res. 17, 293-301 (2010).

47. R. Tonlorenzi, A. Dellavalle, E. Schnapp, G. Cossu, M. Sampaolesi, Isolation and characterization of mesoangioblasts from mouse, dog, and human tissues. Curr. Protoc. Stem Cell Biol. Chapter 2, Unit 2B.1 (2007)

48. Acknowledgments: We thank O. Cappellari, G. Calderazzi, A. Mascaro, L. Perani, M. Takiguchi, L. Biasco, R. Sambasivan, M. Osaki, J. Diaz-Manera, and M. Sampaolesi for helpful comments and S. Tajbakhsh and J. Morgan for critical reading of the manuscript. Funding: Supported by grants from European Research Council, Duchenne Parent Project, Telethon, the Italian Ministries of Research (FIRB) and Health, Fondazione Roma to G.C., and the Ministry of Education, Culture, Sport, Science and Technology of Japan to M.O. Author contributions: F.S.T. conceived and carried out most of the experimental work and analysis and wrote the manuscript; H.H. did DYS-HAC transfer, FISH, and PCR analyses; M.F.M.G. contributed to cell culture, histology, and functional tests; G.D. and R.B. performed force measurements and contributed to manuscript preparation; G.M. did Western blots; S.A. helped with mice and functional tests and isolated satellite cells; R.T. isolated $\mathrm{mdx}$ mesoangioblasts; S.B. performed telomeric repeat amplification protocol (TRAP) assay; L.B. generated MyoD vector; Y.T. provided SCID/mdx mice and discussed results; M.O. and Y.K. coordinated DYS-HAC transfer; G.C. coordinated the project, interpreted the data, and wrote the manuscript with F.S.T. Competing interests: The authors declare that they have no competing interests.

Submitted 2 March 2011

Accepted 29 July 2011

Published 17 August 2011

10.1126/scitransImed.3002342

Citation: F. S. Tedesco, H. Hoshiya, G. D’Antona, M. F. M. Gerli, G. Messina, S. Antonini, R. Tonlorenzi, S. Benedetti, L. Berghella, Y. Torrente, Y. Kazuki, R. Bottinelli, M. Oshimura, G. Cossu, Stem cell-mediated transfer of a human artificial chromosome ameliorates muscular dystrophy. Sci. Transl. Med. 3, 96ra78 (2011). 